\title{
Multivariate bias adjustment of high-dimensional climate simulations: the Rank Resampling for Distributions and Dependences $\left(\mathbf{R}^{2} D^{2}\right)$ bias correction
}

\author{
Mathieu Vrac \\ Laboratoire des Sciences du Climat et de l'Environnement (LSCE-IPSL, CNRS), Centre d'Etudes de Saclay, \\ Orme des Merisiers, 91190 Gif-sur-Yvette, France
}

Correspondence: Mathieu Vrac (mathieu.vrac@1sce.ipsl.fr)

Received: 21 December 2017 - Discussion started: 16 January 2018

Accepted: 22 May 2018 - Published: 7 June 2018

\begin{abstract}
Climate simulations often suffer from statistical biases with respect to observations or reanalyses. It is therefore common to correct (or adjust) those simulations before using them as inputs into impact models. However, most bias correction (BC) methods are univariate and so do not account for the statistical dependences linking the different locations and/or physical variables of interest. In addition, they are often deterministic, and stochasticity is frequently needed to investigate climate uncertainty and to add constrained randomness to climate simulations that do not possess a realistic variability. This study presents a multivariate method of rank resampling for distributions and dependences $\left(R^{2} D^{2}\right)$ bias correction allowing one to adjust not only the univariate distributions but also their inter-variable and inter-site dependence structures. Moreover, the proposed $\mathrm{R}^{2} \mathrm{D}^{2}$ method provides some stochasticity since it can generate as many multivariate corrected outputs as the number of statistical dimensions (i.e., number of grid cell $\times$ number of climate variables) of the simulations to be corrected. It is based on an assumption of stability in time of the dependence structure - making it possible to deal with a high number of statistical dimensions - that lets the climate model drive the temporal properties and their changes in time. $\mathrm{R}^{2} \mathrm{D}^{2}$ is applied on temperature and precipitation reanalysis time series with respect to high-resolution reference data over the southeast of France (1506 grid cell). Bivariate, 1506-dimensional and 3012-dimensional versions of $\mathrm{R}^{2} \mathrm{D}^{2}$ are tested over a historical period and compared to a univariate $\mathrm{BC}$. How the different $\mathrm{BC}$ methods behave in a climate change context is also illustrated with an application to regional climate simulations over the 2071-2100 period. The results indicate that the
\end{abstract}

1d-BC basically reproduces the climate model multivariate properties, $2 d-R^{2} D^{2}$ is only satisfying in the inter-variable context, $1506 \mathrm{~d}-\mathrm{R}^{2} \mathrm{D}^{2}$ strongly improves inter-site properties and $3012 d-R^{2} D^{2}$ is able to account for both. Applications of the proposed $\mathrm{R}^{2} \mathrm{D}^{2}$ method to various climate datasets are relevant for many impact studies. The perspectives of improvements are numerous, such as introducing stochasticity in the dependence itself, questioning its stability assumption, and accounting for temporal properties adjustment while including more physics in the adjustment procedures.

\section{Introduction}

Climate change impact studies aim to investigate and understand the consequences of the potential evolutions of the climate system. Impacts can be hydrological with changes in seasonal flows and water resources driven by precipitation changes (e.g., Schneider et al., 2013), agronomical with crop yields perturbed by heat stress and/or rainfall evolutions (e.g., Müller et al., 2010; Wheeler and von Braun, 2013) and ecological with plant and animal diversity (in terms of structures or spatial repartitions) modified by future climate conditions (e.g., Araújo and Rahbek, 2006; Tisseuil et al., 2012), among many others. The common point of those impact studies is that they use global (GCM) or regional climate model (RCM) simulations of different variables over future time periods according to some scenarios as inputs into impact models to project (e.g., hydrological, ecological) consequences of climate change. However, most of those climate simulations 
suffer from statistical biases with respect to observations or more generally reference data. This means that some of their statistical properties, such as mean, variance, distribution or even temporal, spatial or inter-variable dependence structures may not be representative of what is observed in the reference dataset. Consequently, before employing climate simulations to feed an impact model, it is often mandatory to "bias correct" (or to "adjust") them in order to correct some of their statistical properties (e.g., Christensen et al., 2008; Muerth et al., 2013).

Over the last decade, most of the developed - and therefore applied - bias correction (BC) methods focused on the adjustment of the mean (e.g., Delta method, Xu, 1999), the variance (e.g., simple scaling adjustment, Berg et al., 2012) or more generally on the adjustment of the distribution (e.g., "quantile-mapping", Haddad and Rosenfeld, 1997). Bias adjustments of the whole distribution through quantilemapping techniques have been quite popular since it allows for adjusting not only the mean and variance but also any quantile of the variable of interest. Hence, many variants have been proposed (e.g., Déqué, 2007; Michelangeli et al., 2009; Kallache et al., 2011; Tramblay et al., 2013; Vrac et al., 2016) and applied in different studies (e.g., Oettli et al., 2011; Colette et al., 2012; Tisseuil et al., 2012; Vigaud et al., 2013). Nevertheless, usually, those approaches only work in a univariate context, which means that they are designed to independently correct one variable at a time, for one location (e.g., grid cell) at a time. Therefore, if the marginal (i.e., univariate) distributions are generally improved, that is closer to the reference ones - even when the $\mathrm{BC}$ is used as a preliminary step to downscaling (e.g., Colette et al., 2012; Vrac and Vaittinada Ayar, 2017) - the inter-site and inter-variable dependence structures are usually conserved from the climate model simulations to be corrected. Indeed, 1d-BC methods preserving the ranks of the simulations - as it is the case for quantile-mapping approaches - will not correct the copula functions characterizing the dependencies between sites and/or between variables (e.g., Nelsen, 2006; Schölzel and Friederichs, 2008; Vrac et al., 2011; Bevacqua et al., 2017). Such a preservation of the model dependence can obviously cause some deficiencies in the subsequent impact studies that will use the 1-dimensional bias corrected simulations if the model copula function is far from that of the references. It is therefore crucial to adjust not only the marginal distributions of the climate simulations but also their multivariate dependence structures, which is the goal of the present study. A few multivariate methodologies have been proposed over the last few years (e.g., Bardossy and Pegram, 2012; Piani and Haerter, 2012; Mao et al., 2015; Vrac and Friederichs, 2015; Cannon, 2017; Dekens et al., 2017; Li et al., 2017). Most of these methods can be categorized into one of the two following approaches: the "marginal/dependence" correction approach and the "successive conditional" correction approach. The "marginal/dependence" BC methods (e.g., "matrix recorrelation" approach in Bardossy and Pegram,
2012; Vrac and Friederichs, 2015; Cannon, 2017; Li et al., 2017) separately correct the 1d-marginal distributions (e.g., one variable at one given location) and the dependence structure, usually under the form of the underlying copula function linking the different marginal distributions. Once those two components of the joint distribution have been corrected, they are reassembled to obtain adjusted data that respect both the univariate and multivariate dependencies. Although they also aim to adjust climate simulations in a multivariate fashion, the "successive conditional" BC methods (e.g., "sequential recorrelation" approach in Bardossy and Pegram, 2012; Piani and Haerter, 2012; Dekens et al., 2017) are based on a slightly different philosophy. They consist first of correcting one given variable (e.g., one variable at one specific location). Then, a second variable (e.g., another variable or another location) is corrected conditionally on the previously corrected variable. The procedure goes on successively for each dimension (variable/location), correcting variable $n$ conditionally on previously corrected variables $(1, \ldots, n-1)$. However, this approach suffers from two main limitations. First, since at each step the correction is performed conditionally on previously corrected data, this reduces the number of data available for adjusting each simulation. Consequently, the higher the number of variables to correct, the fewer the number of data to perform the bias correction at each successive step, and therefore the less robust the correction. Second, the ordering of the variables in the successive corrections matters: different orderings generally produce different corrections with different qualitative results (e.g., in terms of multivariate properties; see Piani and Haerter, 2012; Vrac and Friederichs, 2015). For those reasons, the present study deals with the development of a multivariate BC method within the "marginal/dependence" approach. The proposed methodology relies on the "Empirical Copula - Bias Correction" (EC-BC) method (Vrac and Friederichs, 2015) and is intended to fill some of its weaknesses, mainly its lack of flexibility in terms of temporal properties as well as its deterministic aspect. Concerning the time-related weakness, it has to be noted that it is not possible to correct the multidimensional properties of the simulations without changing the rank sequence of the simulations. In other words, any multivariate $\mathrm{BC}$ method will necessarily modify the initial rank chronology of the simulated events. For example, the EC-BC method - belonging to the "marginal/dependence" correction family - allows for both the corrected 1d-distributions to evolve consistently with the modeled ones and to reproduce the dependence (copula) structure of the references. But the price for this reproduction is that the temporal sequence of the ranks of the corrected data is exactly that of the reference data over the calibration time period, even for an adjustment performed over a future time period (or more generally over a projection/correction time period different from the calibration one). Of course, there is no reason why the rank chronology should be the same. This also implies that this multivariate $\mathrm{BC}$ provides 
deterministic corrections, while some studies pointed out the need for stochastic corrections or at least the need for introducing some stochasticity and variability in the BC process (e.g., Wong et al., 2014; Mao et al., 2015; Volosciuk et al., 2017). Hence, the goals of this paper are

- to propose a multivariate $\mathrm{BC}(\mathrm{MBC})$ method for both multi-site and multi-variable simulations;

- to relax the temporal constraints of EC-BC on the corrected data ranks in order to let the climate model drive more temporal properties and their evolutions and therefore express its own temporal dynamics;

- to introduce some stochasticity in the MBC outputs, or at least to enable the proposed MBC method to provide multiple corrected scenarios.

The proposed method relies on a multivariate Rank Resampling for Distributions and Dependences bias correction and will here be referred to as $\mathrm{R}^{2} \mathrm{D}^{2}$. This paper is organized as follows: the reference and reanalysis datasets used in this study are presented in Sect. 2. The $\mathrm{R}^{2} \mathrm{D}^{2}$ method is then described in Sect. 3 after some reminders about the copula theory and the EC-BC approach. The design of experiments performed to evaluate $\mathrm{R}^{2} \mathrm{D}^{2}$ over a historical time period is presented in Sect. 4 and results are provided in Sect. 5. Section 6 displays an application of $\mathrm{R}^{2} \mathrm{D}^{2}$ to $\mathrm{RCM}$ simulations over a future time period. Conclusions, potential future developments and discussions are finally given in Sect. 7.

\section{Reference and model data}

To apply, investigate and evaluate the proposed $\mathrm{R}^{2} \mathrm{D}^{2}$ correction method, a reference dataset and a model dataset to be corrected is needed, as for any BC method. The reference data employed here are daily temperature and precipitation time series from the "Systeme d'Analyze Fournissant des Renseignements Atmosphériques à la Neige" (SAFRAN) reanalysis data (Quintana-Segui et al., 2008) over the southeast region of France $\left(2-7.5^{\circ} \mathrm{E} \times 42-45^{\circ} \mathrm{N}\right)$ corresponding to 1506 continental grid cell with an approximate $8 \mathrm{~km} \times 8 \mathrm{~km}$ spatial resolution. SAFRAN has been described, validated and employed in many studies (e.g., Quintana-Segui et al., 2008; Lavaysse et al., 2012; Vrac et al., 2012).

The ERA-Interim (hereafter ERA-I; Dee et al., 2011) daily reanalysis data with a $0.75^{\circ}$ by $0.75^{\circ}$ spatial resolution are used here as model data to be corrected. Temperature at $2 \mathrm{~m}$ (hereafter T2) and precipitation data (hereafter PR) have been extracted for the same spatial domain as for the reference data. The time period from 1 January 1980 to 31 December 2009 is retained for both reference and ERA-I data. Then, each ERA-I grid cell is first regridded by a simple nearest neighbor technique to the nearest SAFRAN grid cell center, in order to be associated with a unique reference
SAFRAN grid cell. Next, each BC method to be tested is applied over two distinct periods of the year: one corresponding loosely to "winter" from 15 October to 14 April, the other to "summer" from 15 April to 14 October. For each "season", corrected ERA-I T2 and PR are obtained for the 1995-2009 "evaluation" time period based on BC models calibrated over 1980-1994. Note that, as they potentially still include some seasonality (especially in temperature), 6-month long seasons to condition the $\mathrm{BC}$ procedures are certainly not the most suited time intervals for practical use or applications. In the latter cases, regular 3-month seasons or even monthly conditioning could be preferred, provided that enough data are available for calibration and projection. This could nevertheless introduce some artificial "discontinuities" when going from one month or season to another, which may be detrimental to some specific applications. However, here, 6month seasons correspond to a very convenient cutting for testing and illustrating how a newly developed BC method behaves, which is the main purpose of this article. Indeed, this cutting allows for (1) increasing the number of data points (e.g., with respect to a monthly cutting) and (2) restricting the number of figures and evaluations that would be multiplied by two in case of 3-month seasons, or by six with a monthly cutting.

Moreover, Sect. 6 of this article will present an illustration of how the suggested $\mathrm{R}^{2} \mathrm{D}^{2}$ method works when applied to RCMs, both in present and future climates. Nevertheless, the ERA-I reanalyses are primarily used as test data to be corrected because they ensure some consistency with the SAFRAN reference dataset. Indeed, when employing RCM data in a cross-validation context (or more generally when applying a BC method to RCM data over a projection time period different from the calibration time period), the changes in statistical properties (e.g., mean, variance) from the calibration to the projection time periods can be different for the reference and for the RCM data. Hence, when evaluating the results of a $\mathrm{BC}$ method over a projection period, it may be difficult to assess which remaining biases come from the disagreement between reference and RCM changes, and which come from the $\mathrm{BC}$ method itself. Using reanalysis data ensures more consistency with the reference and is therefore more appropriate for initial evaluation of a BC method.

\section{Reconstructing multi-site and multi-variable dependence structures}

\subsection{A brief reminder on copulas}

In many of the multivariate $\mathrm{BC}$ development papers, the notion of "copula functions" is used. Indeed, those functions characterize the rank dependence structure of most multivariate joint distributions (e.g., Nelsen, 2006; Schölzel and Friederichs, 2008) through the Sklar's theorem (Sklar, 1959). This theorem expresses that any multivariate cumulative dis- 
tribution function (CDF) can be described by the univariate marginal CDFs of the multivariate random variable and a copula function. The latter is itself a multivariate CDF depicting the statistical dependence of the transformed random variables $U_{j}=F_{X_{j}}\left(X_{j}\right)$, where $X_{j}$ is the $j$-th variable of the $d$-dimensional random variable $X=\left(X_{1}, \ldots, X_{d}\right)^{T}$ and $F_{X_{j}}$ the respective marginal CDF. Mathematically, Sklar's theorem states that any multivariate $\mathrm{CDF} F_{\mathbf{X}}$ (e.g., temperature at several stations) can be written as

$F_{X}=C_{X}\left(F_{X_{1}}, \ldots, F_{X_{d}}\right)$,

where $C_{\boldsymbol{X}}$ is the copula of $\boldsymbol{X}$. Therefore, any multivariate BC method will necessarily correct the copula of the simulations, explicitly (e.g., Piani and Haerter, 2012; Vrac and Friederichs, 2015) or implicitly (e.g., Cannon, 2017; Dekens et al., 2017).

\subsection{A brief reminder of the "Empirical Copula - Bias Correction" (EC-BC) approach}

The EC-BC approach (Vrac and Friederichs, 2015) takes advantage of the so-called "Schaake Shuffle", described by Clark et al. (2004) and employed in various studies to reconstruct multivariate dependence structures (e.g., Voisin et al., 2010; Verkade et al., 2013; Cannon, 2017, among others). The principle is the following: first, a $1 \mathrm{~d}-\mathrm{BC}$ is performed on each statistical dimension (i.e., for each variable at each location). Second, the univariate bias corrected data are reordered such that their rank time series is identical to that of the reference sample. This univariate shuffling performed separately on each variable allows us to reproduce both the temporal, inter-site and inter-variable dependencies of the reference data (see the synthetic example in Table 1 of Sect. 4c in Vrac and Friederichs, 2015), since it exactly reproduces the empirical copula function of the references. However, if the inter-site and inter-variable dependence structures can be assumed to be stable over time because they can be considered to be imposed by physical constraints over the region of interest, this is not the case for the temporal structures (or rank chronology of the climate events). For example, rain persistence can shorten or enlarge, or heat waves can increase and/or be more frequent, and seasonality of some specific (temperature or precipitation) events may change, depending on the geographical domain. It is therefore needed to relax the EC-BC temporal constraint to let the climate simulations express their temporal dynamics and evolutions through time. This is the goal of the proposed methodology.

\subsection{The Rank Resampling for Distributions and Dependences $\left(\mathbf{R}^{2} \mathbf{D}^{2}\right)$ bias correction approach}

The $\mathrm{R}^{2} \mathrm{D}^{2}$ method is developed in the "marginal/dependence" context: The main idea of $\mathrm{R}^{2} \mathrm{D}^{2}$ is to take advantage of the Schaake Shuffle as in EC-BC but to relax the constraint of the reproduction of the temporal structure observed in the reference dataset. To do so, a historical time period is used as the calibration time period for which both climate simulations and reference datasets are at one's disposal. The correction is performed over a projection time period (e.g., a future time period) where only climate simulations are available. The $\mathrm{R}^{2} \mathrm{D}^{2}$ method proceeds as follows (please refer to Appendix A for a detailed mathematical description of the $\mathrm{R}^{2} \mathrm{D}^{2}$ algorithm):

1. As in EC-BC or any "marginal/dependence" approach, each dimension (variable/location) is first corrected independently from the others by a univariate BC method. In the present study, the CDF-t method is used (e.g., Vrac et al., 2012).

2. Then, a dimension is selected (i.e., one physical variable at one given location) to serve as a "reference dimension" for the shuffling. For this specific dimension, the time sequence of the ranks of the 1d-bias-corrected data is kept untouched. Note that this sequence is therefore the same as that of the ranks of the simulations to be corrected, at least with a $\mathrm{BC}$ method preserving the ranks as it is the case for CDF-t.

3. Next, for each time step $t$ of the projection time period, $\mathrm{R}^{2} \mathrm{D}^{2}$ looks for the time step $t^{*}$ in the calibration time period for which the rank of the reference dimension is the same as the current rank of the reference dimension, i.e., $\mathrm{R}^{2} \mathrm{D}^{2}$ searches $t^{*}$ such that $\operatorname{rank}_{\mathrm{dim}}{ }^{1 \mathrm{~d}-\mathrm{BC}}(t)=$ $\operatorname{rank}_{\operatorname{dim}}{ }^{\text {ref.data }}\left(t^{*}\right)$, where $\operatorname{rank}_{\operatorname{dim}^{A}}{ }^{A}(t)$ is the rank - in the dataset $A$ - of the value taken by the reference dimension $\operatorname{dim}$ at time step $t$.

4. Once this time step $t^{*}$ is found, the time series of the other dimensions (i.e., the other variables at the same location, and all variables at the other locations) are shuffled such that the inter-site and inter-variable rank structures of the reference dataset are reproduced. This means that the rank association found in the reference dataset for time $t^{*}$ is reproduced for time $t$.

5. Steps 2 to 4 are then repeated successively until each dimension has served as the reference dimension.

Those different steps are expressed in more mathematical and algorithmic ways in the Appendix A.

An example is now given to illustrate the functioning of $\mathrm{R}^{2} \mathrm{D}^{2}$. Let's assume that the multivariate bias correction problem of interest concerns $P=3$ statistical dimensions. Those can be one physical variable for three grid cell, or three physical variables for one grid cell. Each dimension is simulated and observed over $N=4$ consecutive time steps (e.g., days). Of course, in practice, many more variables, grid cell and time steps can be treated. Let's say that the first step of independent univariate bias correction was performed and that the reference and 1d-bias-corrected data are those given in Table 1, where each second column indicates the ranks of the 
Table 1. One example of 3-dimensional reference data and results from the 1d-bias correction of sample size 4 for illustration of the $\mathrm{R}^{2} \mathrm{D}^{2}$ method. $k()$ indicates the rank within the sample.

\begin{tabular}{rrrrrr|rrrrrr}
\hline \multicolumn{7}{c}{ References } & \multicolumn{7}{c}{ 1d-BC } \\
\hline$x_{R}^{(i)}$ & $k\left(x_{R}^{(i)}\right)$ & $y_{R}^{(i)}$ & $k\left(y_{R}^{(i)}\right)$ & $z_{R}^{(i)}$ & $k\left(z_{R}^{(i)}\right)$ & $x_{1 d}^{(i)}$ & $k\left(x_{1 d}^{(i)}\right)$ & $y_{1 d}^{(i)}$ & $k\left(y_{1 d}^{(i)}\right)$ & $z_{1 d}^{(i)}$ & $k\left(z_{1 d}^{(i)}\right)$ \\
\hline 0.3 & 1 & 1.1 & 1 & 2.1 & 2 & 0.7 & 3 & 1.3 & 2 & 1.9 & 1 \\
0.5 & 2 & 1.7 & 3 & 1.8 & 1 & 0.5 & 2 & 1.8 & 4 & 2.9 & 4 \\
0.9 & 4 & 1.2 & 2 & 3.0 & 4 & 0.2 & 1 & 1.1 & 1 & 2.0 & 2 \\
0.8 & 3 & 1.9 & 4 & 2.7 & 3 & 0.9 & 4 & 1.4 & 3 & 2.6 & 3 \\
\hline
\end{tabular}

Table 2. Results of the $\mathrm{R}^{2} \mathrm{D}^{2}$ correction method. As the initial data are 3-dimensional, three time series are provided by $\mathrm{R}^{2} \mathrm{D}^{2}$. The $k$ indicates the rank within the sample. Within each 3-dimensional time series, the bold values and ranks indicate the dimension and rank sequence taken as reference.

\begin{tabular}{cccccc|ccccccc|cccccc}
\hline \multicolumn{4}{c}{$3 \mathrm{~d}-\mathrm{BC}(1 / 3)$} & \multicolumn{4}{c}{$3 \mathrm{~d}-\mathrm{BC}(2 / 3)$} & \multicolumn{4}{c}{$3 \mathrm{~d}-\mathrm{BC}(3 / 3)$} \\
\hline$x^{(i)}$ & $k$ & $y^{(i)}$ & $k$ & $z^{(i)}$ & $k$ & $x^{(i)}$ & $k$ & $y^{(i)}$ & $k$ & $z^{(i)}$ & $k$ & $x^{(i)}$ & $k$ & $y^{(i)}$ & $k$ & $z^{(i)}$ & $k$ \\
\hline $\mathbf{0 . 7}$ & $\mathbf{3}$ & 1.8 & 4 & 2.6 & 3 & 0.9 & 4 & $\mathbf{1 . 3}$ & $\mathbf{2}$ & 2.9 & 4 & 0.5 & 2 & 1.4 & 3 & $\mathbf{1 . 9}$ & $\mathbf{1}$ \\
$\mathbf{0 . 5}$ & $\mathbf{2}$ & 1.4 & 3 & 1.9 & 1 & 0.7 & 3 & $\mathbf{1 . 8}$ & $\mathbf{4}$ & 2.6 & 3 & 0.9 & 4 & 1.3 & 2 & $\mathbf{2 . 9}$ & $\mathbf{4}$ \\
$\mathbf{0 . 2}$ & $\mathbf{1}$ & 1.1 & 1 & 2.0 & 2 & 0.2 & 1 & $\mathbf{1 . 1}$ & $\mathbf{1}$ & 2.0 & 2 & 0.2 & 1 & 1.1 & 1 & $\mathbf{2 . 0}$ & $\mathbf{2}$ \\
$\mathbf{0 . 9}$ & $\mathbf{4}$ & 1.3 & 2 & 2.9 & 4 & 0.5 & 2 & $\mathbf{1 . 4}$ & $\mathbf{3}$ & 1.9 & 1 & 0.7 & 3 & 1.8 & 4 & $\mathbf{2 . 6}$ & $\mathbf{3}$ \\
\hline
\end{tabular}

values in the time series displayed in the previous column. The results provided by $\mathrm{R}^{2} \mathrm{D}^{2}$ are given in Table 2. First, a reference dimension is selected, starting with $x$ in this illustration, and the $1 \mathrm{~d}-\mathrm{BC}$ time series of this dimension is preserved at this stage. We can note that the first column of "3dBC (1/3)" in Table 2 is therefore the same as that given by the univariate $\mathrm{BC}$ of dimension $x$ in Table 1 . Then, for each time step (i.e., row in those two tables), the rank of the current $1 \mathrm{~d}-\mathrm{BC}$ value is calculated. The time step with the same rank is then searched into the reference data for this dimension (here, $x$, first and second columns in Table 1) and the ranks of the other dimensions $y$ and $z$ for this time step are taken to shuffle the 1d-corrections of those two dimensions. For example, for the first time step in Table 2, the value 0.7 of the reference dimension $x$ has rank 3. Looking into Table 1, rank 3 is found at the last time step for $x$, and is associated with ranks 4 and 3 for $y$ and $z$, respectively. Therefore, the $x=0.7$ value is associated with values 1.8 and 2.6, which have ranks 4 and 3 for $y$ and $z$, respectively, in the univariate bias correction (Table 1). This procedure is then repeated for each time step before changing the reference dimension and rank sequence. $\mathrm{R}^{2} \mathrm{D}^{2}$ then provides as many corrections as the total number dimensions - or at least as many as the number of reference dimensions employed. Indeed, for practical reasons, it may be necessary to apply this algorithm on a reduced number of reference dimensions, therefore reducing the number of corrected outputs. However, whatever the number of reference dimensions or correction scenarios selected, the multivariate corrected data should all have equivalent inter-site and inter-variable copula functions.
Moreover, step 4 assumes that these copula (dependence) functions are stable in time (i.e., stationary) and correspond to those from the reference data. This assumption makes it possible to apply the proposed $\mathrm{R}^{2} \mathrm{D}^{2}$ method in a highdimensional context, e.g., more than 3000 statistical dimensions as will be illustrated in the following sections.

In the present study, the CDF-t univariate adjustment method (e.g., Vrac et al., 2012) is used to perform step 1 of the above algorithm. For the precipitation variable, CDF-t has been applied based on the relatively common "threshold adaptation" procedure. It consists of first defining a threshold th for which model data below th are set to zero (e.g., Schmidli et al., 2006; Lavaysse et al., 2012). This threshold is chosen such that the frequency of days with model precipitation greater than th is the same as the frequency of rainy days in the reference (observed) precipitation dataset. After this thresholding, only the positive values are corrected by CDF-t with respect to the strictly positive observed values. Other approaches are possible, such as applying a BC model directly on the whole time series including both dry days and rainy days, i.e., without separating the correction methodology into occurrence and intensity (e.g., Vrac et al., 2012; Vigaud et al., 2013; Vrac et al., 2016, among others). The latter approach has also been tested for preliminary tests and the results were not sensibly different from those presented in this article (not shown). Note also that other 1d-BC methods can of course be employed instead of CDF-t. For example, the regular quantile-mapping approach (e.g., Déqué, 2007) has also been tested within $\mathrm{R}^{2} \mathrm{D}^{2}$ and similar results were obtained (not shown). 


\section{Design of experiments}

This section describes the comparisons that will be performed between different $\mathrm{BC}$ methods in the following for evaluating the proposed $\mathrm{R}^{2} \mathrm{D}^{2}$ bias correction methodology.

It is first reminded that, for each tested BC method applied to ERA-I reanalyses with SAFRAN data as reference, the calibration period is 1980-1994, while the correction/evaluation period is 1995-2009. Moreover, each calibration/evaluation is performed for daily temperature and precipitation time series on 1506 grid cell in the southeast of France over a 6-month "winter" (15 October to 14 April) and a 6-month "summer" (15 April to 14 October).

First of all, the 1-dimensional CDF-t bias correction (e.g., Michelangeli et al., 2009; Vrac et al., 2012) is performed. As it is also the $1 \mathrm{~d}-\mathrm{BC}$ method used in step 1 of the $\mathrm{R}^{2} \mathrm{D}^{2}$ algorithm, this will allow us to evaluate the contribution of the other steps in $\mathrm{R}^{2} \mathrm{D}^{2}$. Then, various configurations of the $R^{2} D^{2}$ method are applied and evaluated:

- a 2-dimensional $\mathrm{R}^{2} \mathrm{D}^{2}$ version, where each grid cell is corrected independently but temperature and precipitation are corrected jointly within each grid cell. As there are 1506 grid cell for the present dataset, 1506 applications of $2 d-R^{2} D^{2}$ are realized;

- a 1506-dimensional $\mathrm{R}^{2} \mathrm{D}^{2}$ version, where all 1506 grid cell time series are corrected jointly but separately in temperature and precipitation. Therefore, two 1506d$\mathrm{R}^{2} \mathrm{D}^{2}$ are realized, one for temperature and one for precipitation;

- a 3012-dimensional version, where temperature and precipitation for all the 1506 grid cell are corrected jointly. Only one $3012 \mathrm{~d}-\mathrm{BC}$ is needed here.

Note that, as $\mathrm{R}^{2} \mathrm{D}^{2}$ can return as many datasets (or "scenarios") of correction as the number of statistical dimensions, the $2 \mathrm{~d}-\mathrm{R}^{2} \mathrm{D}^{2}$ versions return two corrected datasets for each grid cell. However, for the $1506 \mathrm{~d}-$ and $3012 \mathrm{~d}-\mathrm{R}^{2} \mathrm{D}^{2}$ versions, a sub-sample of 10 reference dimensions has been selected for each version. Therefore, those versions provide 10 corrected datasets. The 10 reference dimensions have been chosen to uniformly cover the geographical domain for each physical variable.

In the following Sect. 5, the results of those four BC methods (1d, 2d, 1506d, 3012d) as well as the initial dataset to be corrected (ERA-I) are compared according to three different aspects evaluated on the 1995-2009 evaluation period. First, the inter-variable dependence properties are investigated in Sect. 5.1. Second, the inter-site dependence structures are compared in Sect. 5.2. Finally, although this aspect was not part of the correction design, the temporal properties are also evaluated in Sect. 5.3. Indeed, as any multivariate BC method will necessarily modify the initial rank chronology of the simulated events, it is interesting to understand or at least to quantify - these modifications.

\section{Results}

In this section, all analyses are realized for the winter season but the main conclusions hold for the summer results that are displayed in the Supplement.

\subsection{Inter-variable correlations}

First, the $\mathrm{BC}$ results are compared in terms of inter-variable correlations. To do so, the spearman correlation between temperature and precipitation time series have been computed for each of the 1506 grid cell and the resulting maps are shown in Fig. 1. Note that the Pearson correlation maps have also been computed. The results were very similar (not shown) but, based on Pearson correlations, a larger gap between the ERA-I Pearson correlations Fig. $1 b$ and the reference SAFRAN Pearson correlations Fig. 1a means that most maps only use a reduced number of colors, which is not convenient for visual evaluations. This is why only the Spearman correlation is used in Fig. 1. In this figure, it is clear that the ERA-I inter-variable correlation map Fig. $1 \mathrm{~b}$ is very different from that of SAFRAN (a), with spearman rank correlations not only differing in their intensities but also in their structure. This strongly exemplifies the need for adjustment of this aspect. The 1d-BC CDF-t method Fig. 1c modifies the intensities of those correlations but does not change its structure, basically conserving that of ERA-I. However, the $2 \mathrm{~d}$ - and $3012 \mathrm{~d}-\mathrm{R}^{2} \mathrm{D}^{2}$ methods (Fig. $1 \mathrm{~d}$ and $\mathrm{f}$, respectively) provide major improvements, since they allow us to approximate the temperature-precipitation correlations from SAFRAN (a). Correlation maps from those two $\mathrm{R}^{2} \mathrm{D}^{2}$ versions are strictly the same, indicating that the 3012d-version is a generalization of the 2d-configuration (at least in this inter-variable evaluation context). This is not the case for the $1506 \mathrm{~d}-\mathrm{R}^{2} \mathrm{D}^{2}$ configuration that basically destroys the intervariable correlations. Indeed, as in this configuration, temperature and precipitation are adjusted separately and independently from each other, the obtained correlations are - by construction - close to 0 . This version is designed to take care of the inter-site dependence but completely disregards and even ruins inter-variable correlations. Note that the 3012d$\mathrm{R}^{2} \mathrm{D}^{2}$ configuration provides the same correlation map as presented in Fig. 1.f, whatever the reference dimension selected. This is also true for the $2 \mathrm{~d}$ - and $1506 \mathrm{~d}$-versions where a different reference dimension still generates equivalent correlations.

\subsection{Spatial correlations}

The evaluation is now performed in terms of inter-site and spatial correlation. A principal component analysis (PCA) is first carried out on each physical variable (i.e., temperature and precipitation) separately but for the whole region of interest (i.e., 1506 grid cell). However, before applying the PCA, the daily areal mean has been removed from each 

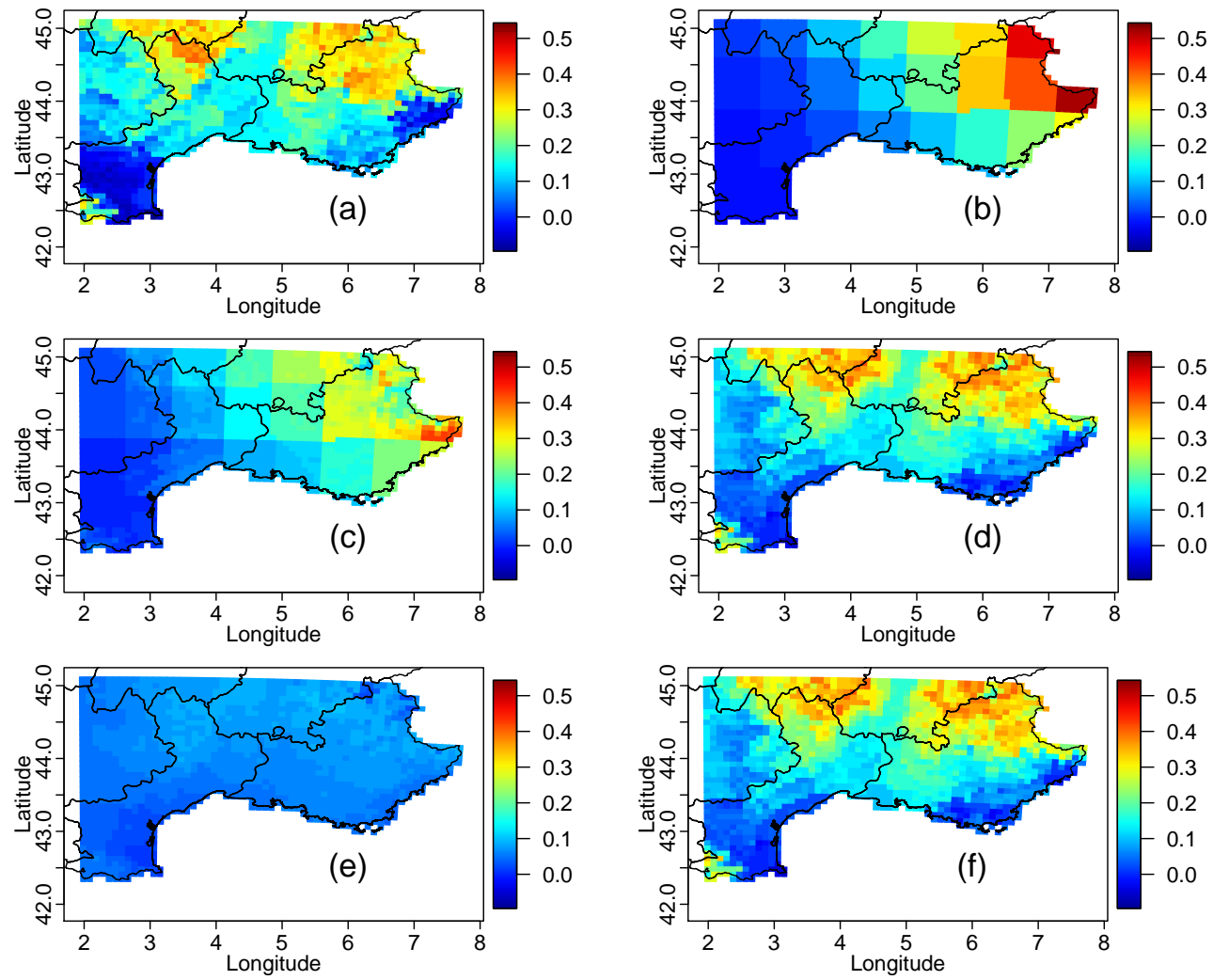

Figure 1. Inter-variable Spearman correlation maps in winter over the evaluation period from: (a) SAFRAN; (b) ERA-I; (c) 1d-BC (CDF-t); (d) $2 \mathrm{~d}-\mathrm{R}^{2} \mathrm{D}^{2}$; (e) $1506 \mathrm{~d}-\mathrm{R}^{2} \mathrm{D}^{2}$ on temperature and $1506 \mathrm{~d}-\mathrm{R}^{2} \mathrm{D}^{2}$ on precipitation; (f) $3012 \mathrm{~d}-\mathrm{R}^{2} \mathrm{D}^{2}$.

daily data. Indeed, the data present a high day-to-day variability within the region of interest. This strongly impacts the PCA that shows a predominant empirical orthogonal function (EOF) almost uniform over the region if the areal mean is not removed (not shown). Moreover, as precipitation presents a skewed distribution, all zero precipitation values are put to a non-zero but positive small value $\left(3.3^{-4}\right)$ and the precipitation PCA is performed on the logarithm of the values (following, e.g., Vrac and Friederichs, 2015), where the areal mean has been removed. Although the log-precipitation values look more Gaussian than the initial ones, a PCA on those transformed data should still be interpreted with prudence. This is nevertheless a helpful means to describe spatial modes of variability. Figures 2 and 3 show the maps of the first EOFs obtained from PCAs applied to temperature or log-precipitation, respectively, from the different datasets. For both variables, ERA-I first EOF (Figs. $2 b$ and $3 b$ ) maps are quite dissimilar from the SAFRAN EOF maps (Figs. 2a and 3a). The univariate BC (Figs. 2c and 3c) shows similar results as those from ERA-I, although less pronounced for precipitation (Fig. 3c). Concerning the results of the 2dimensional version of $\mathrm{R}^{2} \mathrm{D}^{2}$ (Figs. $2 \mathrm{~d}$ and $3 \mathrm{~d}$ ), for each grid cell, they are obtained based on selecting as reference dimension the "other" dimension. In other words, for precipita- tion the reference dimension is temperature, and for temperature the reference dimension is precipitation. Indeed, otherwise (i.e., if the reference dimension is the variable of interest), by construction, the spatial structures resulting from the $2 d-R^{2} D^{2}$ are exactly the same as those from the $1 d-B C$ presented in Figs. $2 \mathrm{c}$ and $3 \mathrm{c}$ (not shown). In the present configuration of the $2 d-R^{2} D^{2}$ version, the spatial modes of variability (in Figs. 2d and 3d) are different from both the ERA-I and $1 \mathrm{~d}-\mathrm{BC}$ results. They visually look more similar to the SAFRAN results and seem to improve the inter-site dependence structure. But this is not the case for summer results (see Supplement) and they do present some major differences with respect to SAFRAN for both precipitation and temperature in the two seasons. However, the first EOF maps from the 1506-dimensional (Figs. 2e and 3e) and the 3012dimensional versions (Figs. $2 \mathrm{f}$ and $3 \mathrm{f}$ ) are very close to those from the reference SAFRAN dataset, indicating a satisfying modeling of the main modes of inter-site variability, both for temperature and (log-) precipitation. This is also confirmed by the eigenvalues and explained variance fractions of the leading EOF for temperature and log-precipitation given in Fig. 4, as well as by the correlograms (i.e., correlations in function of the distance) displayed in Fig. 5. In those figures, the results of the $1506 \mathrm{~d}-$ and $3012 \mathrm{~d}-\mathrm{R}^{2} \mathrm{D}^{2}$ versions are 

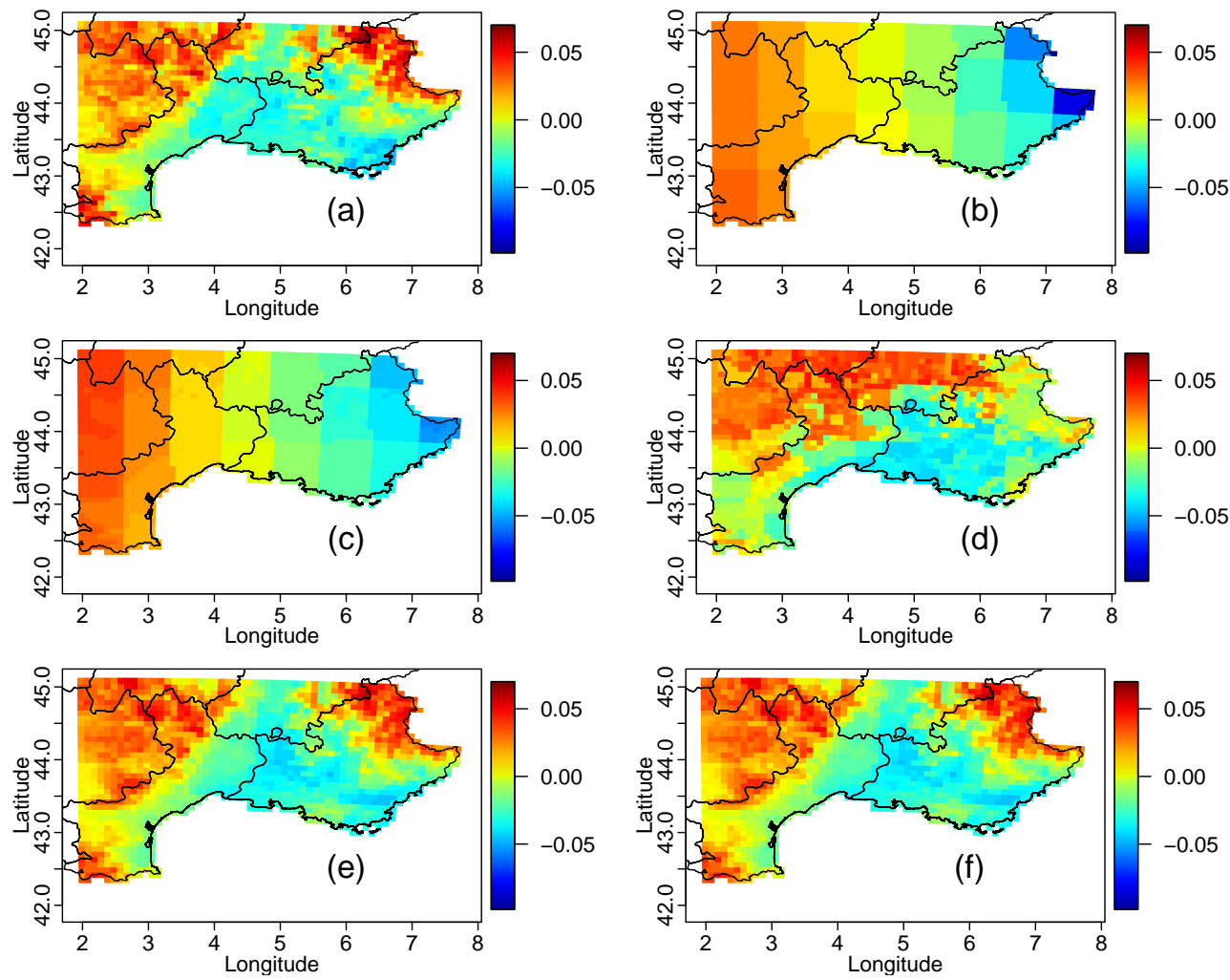

Figure 2. Maps of first temperature predominant empirical orthogonal functions (EOFs) in winter over the evaluation period for (a) SAFRAN; (b) ERA-I; (c) 1d-BC (CDF-t); (d) 2d-R $\mathrm{R}^{2}$ (with PR as reference dimension); (e) $1506 \mathrm{~d}-\mathrm{R}^{2} \mathrm{D}^{2}$ (on T2 only); (f) $3012 \mathrm{~d}-$ $\mathrm{R}^{2} \mathrm{D}^{2}$.

the same: they stick closely to the SAFRAN eigenvalues and explained variances (Fig. 4) and reproduce well its correlogram (Fig. 5), even at long distances. The other datasets show deviations from SAFRAN more or less pronounced and in agreement with previous Figs. 2 and 3: ERA-I results are relatively far away from SAFRAN, 1d-BC slightly modifies the spatial properties but stays comparable to ERAI and $2 \mathrm{~d}-\mathrm{R}^{2} \mathrm{D}^{2}$ degrades the ERA-I spatial properties (at least in the present configuration). The same conclusions hold for summer (see the Supplement) where the 1506d- and 3012d$\mathrm{R}^{2} \mathrm{D}^{2}$ versions follow SAFRAN spatial properties, although some differences appear between the correlograms at long distances ( $>400 \mathrm{~km}$ ) especially for temperature.

In order to get more quantification of those results, various Spearman and Pearson correlation matrices was computed for the different datasets (SAFRAN, ERA-I and the BC results) in the evaluation period over the 1506 locations:

- on temperature vs. temperature (resulting in a $1506 \times 1506$ spatial correlation matrix);

- on precipitation vs. precipitation $(1506 \times 1506$ spatial correlation matrix);

- on temperature vs. precipitation $(1506 \times 1506$ spatial correlation matrix across the two variables);
- on (temperature, precipitation) vs. (temperature, precipitation) $(3012 \times 3012$ spatial and inter-variable correlation matrix).

The SAFRAN correlation matrix is then subtracted from the correlation matrix of each dataset (ERA-I and the BC results), therefore providing matrices that describe differences

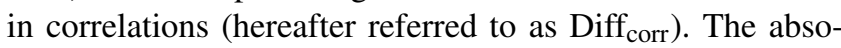
lute values of the elements of this matrix are then summed and the result - noted $S_{\text {corr }}$ - gives a numerical indication of the global quality of the dataset dependence structure with respect to that of SAFRAN. The values of $S_{\text {corr }}$ for each dataset and for the different types of correlations are given in Table 3. The results for the "T2 vs. T2" and "PR vs. PR" correlations are quite similar, showing the good behavior of the $1506 \mathrm{~d}$ - and $3012 \mathrm{~d}-\mathrm{BC}$ methods, while it is clear that the $2 \mathrm{~d}-\mathrm{R}^{2} \mathrm{D}^{2}$ version deteriorates the ERA-I and $1 \mathrm{~d}-\mathrm{BC}$ correlations. For the "T2 vs. PR" correlations, the $2 \mathrm{~d}-\mathrm{BC}$ version is relatively equivalent to the ERA-I and $1 \mathrm{~d}-\mathrm{BC}$ but the $1506 d-R^{2} D^{2}$ slightly degrades those results, while the $3012-$ dimensional version is much better. Finally, for the "(T2,PR) vs. (T2,PR)" correlations, the $2 \mathrm{~d}-\mathrm{BC}$ version appears as not adapted, the 1506d-BC improves ERA-I and the 1d-BC but $3012 d-R^{2} D^{2}$ provides the best results. 

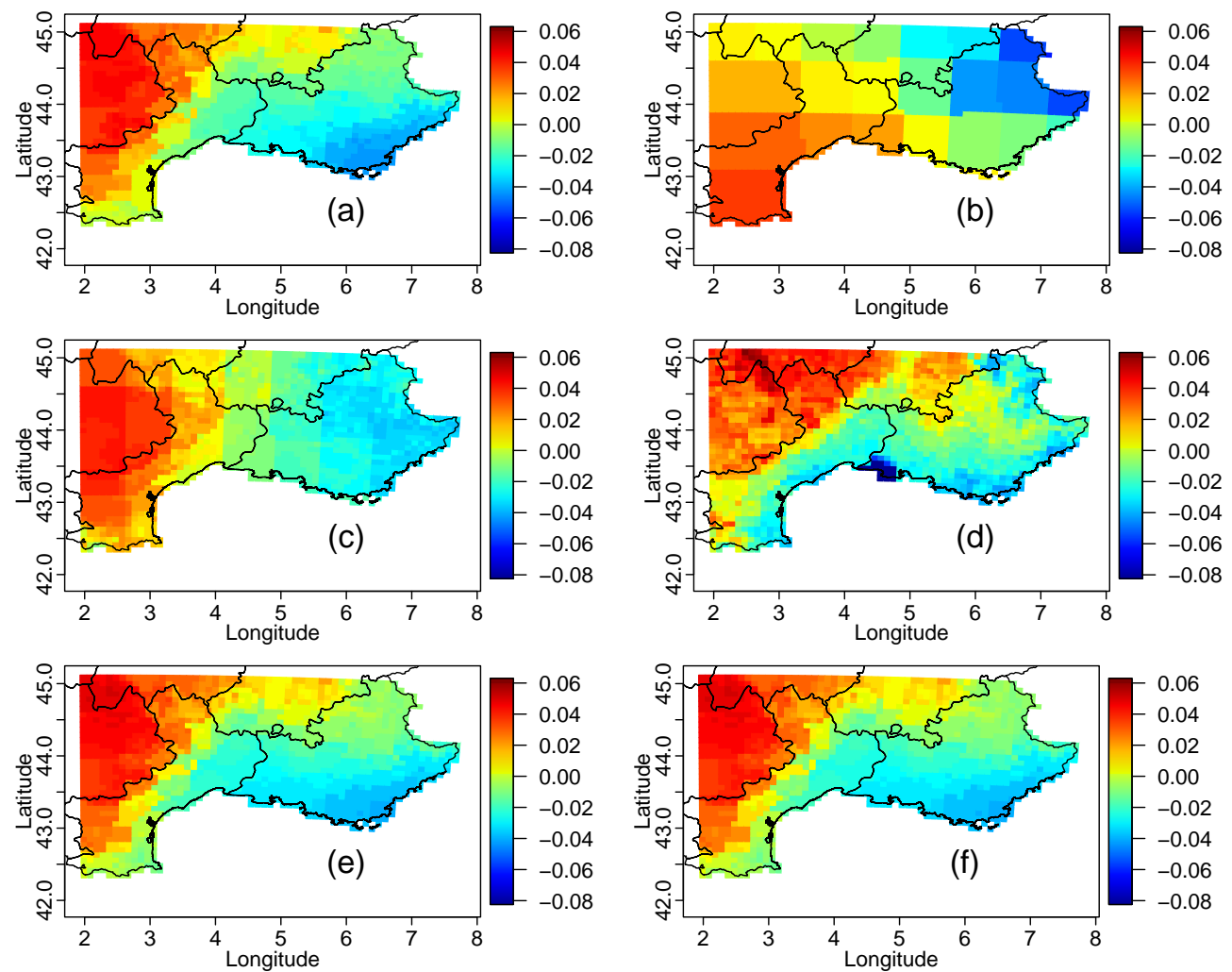

Figure 3. Same as Fig. 2 but for precipitation.

Table 3. Values of $S_{\text {corr }}$, corresponding to the sum of the absolute values of the elements of the difference correlation matrices for each dataset and for the different types of correlations (see text for details) in winter. Values have to be multiplied by $10^{4}$. Some methods and

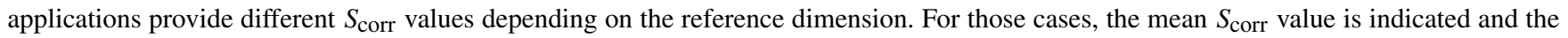
standard deviation is indicated between brackets. Values in bold font indicate the smallest values for the line.

\begin{tabular}{lrrrrr}
\hline & ERA-I & $1 \mathrm{~d}-\mathrm{BC}$ & $2 \mathrm{~d}-\mathrm{R}^{2} \mathrm{D}^{2}$ & $1506 \mathrm{~d}-\mathrm{R}^{2} \mathrm{D}^{2}(\mathrm{~T} 2$ or PR $)$ & $3012 \mathrm{~d}-\mathrm{R}^{2} \mathrm{D}^{2}$ \\
\hline Spearman (T) & 20.1 & 20.1 & $96.4( \pm 107.9)$ & $\mathbf{5 . 4}$ & $\mathbf{5 . 4}$ \\
Pearson (T) & 19 & 18.6 & $96.3( \pm 109.8)$ & $\mathbf{4 . 8}$ & $\mathbf{4 . 8}$ \\
\hline Spearman (PR) & 69 & 40.6 & $73.6( \pm 46.7)$ & $\mathbf{5 . 8}$ & $\mathbf{5 . 8}$ \\
Pearson (PR) & 87.9 & 62.1 & $74.7( \pm 17.8)$ & $\mathbf{1 0 . 4}$ & $\mathbf{1 0 . 4}$ \\
\hline Spearman (T2 vs. PR) & 25.8 & 24.5 & $23.4( \pm 11)$ & $30.4( \pm 5.8)$ & $\mathbf{8}$ \\
Pearson (T2 vs. PR) & 16.3 & 13.3 & $14.8( \pm 6.7)$ & $71.9( \pm 11.6)$ & $\mathbf{5 . 7}$ \\
\hline Spearman (T and PR) & 140.7 & 109.6 & $216.7( \pm 83.2)$ & $\mathbf{2 7}$ \\
Pearson (T and PR) & 139.5 & 107.3 & $200.6( \pm 105.5)$ & $\mathbf{2 6 . 6}$ \\
\hline
\end{tabular}

Other analyses of the spatial properties derived for the different $\mathrm{BC}$ methods were also performed (e.g., quantilequantile plots of the daily areal means) but are not provided here since their conclusions were the same as in the presented figures: 1d-BC approximately preserves ERA-I properties that are biased with respect to SAFRAN's; 2d-BC changes the ERA-I spatial statistics but does not necessarily improve them, while $1506 \mathrm{~d}$ - and $3012 \mathrm{~d}-\mathrm{BC}$ via $\mathrm{R}^{2} \mathrm{D}^{2}$ provides satis- fying spatial variability and dependence structures, close to those from SAFRAN.

\subsection{Temporal correlations}

The proposed $\mathrm{R}^{2} \mathrm{D}^{2}$ method is not designed to reproduce, correct or preserve the temporal structure of the simulations to be corrected. However, as any multivariate $\mathrm{BC}$ will necessarily modify their rank sequence, it is interesting to under- 

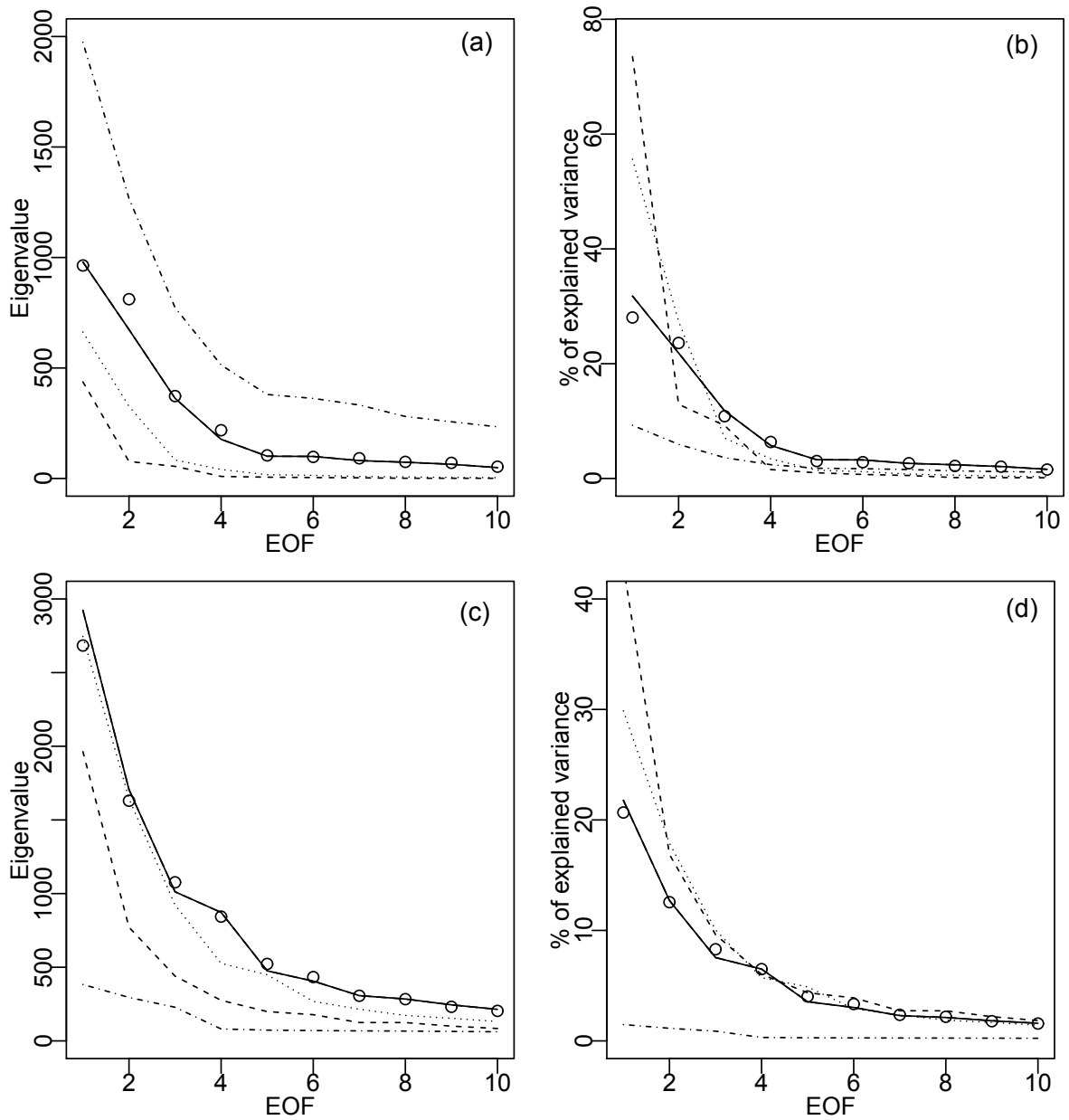

Figure 4. Eigenvalues $(\mathbf{a}, \mathbf{c})$ and percentage of explained variance $(\mathbf{b}, \mathbf{d})$ of temperature at $2 \mathrm{~m}(\mathbf{a}, \mathbf{b})$ and precipitation $(\mathbf{c}, \mathbf{d})$ in winter over the evaluation period for: SAFRAN (circles); ERA-I (dashed); $1 \mathrm{~d}-\mathrm{BC}$ by CDF-t (dotted); $2 \mathrm{~d}^{-\mathrm{R}^{2}} \mathrm{D}^{2}$ (dashed-dotted); $1506 \mathrm{~d}-\mathrm{R}^{2} \mathrm{D}^{2}$ (T2 or PR, long dashed); $3012 \mathrm{~d}-\mathrm{R}^{2} \mathrm{D}^{2}$ (solid line). Note that results of the $1506 \mathrm{~d}$ - (long dashed) and $3012 \mathrm{~d}-\mathrm{R}^{2} \mathrm{D}^{2}$ (solid line) versions are the same and are therefore superimposed.
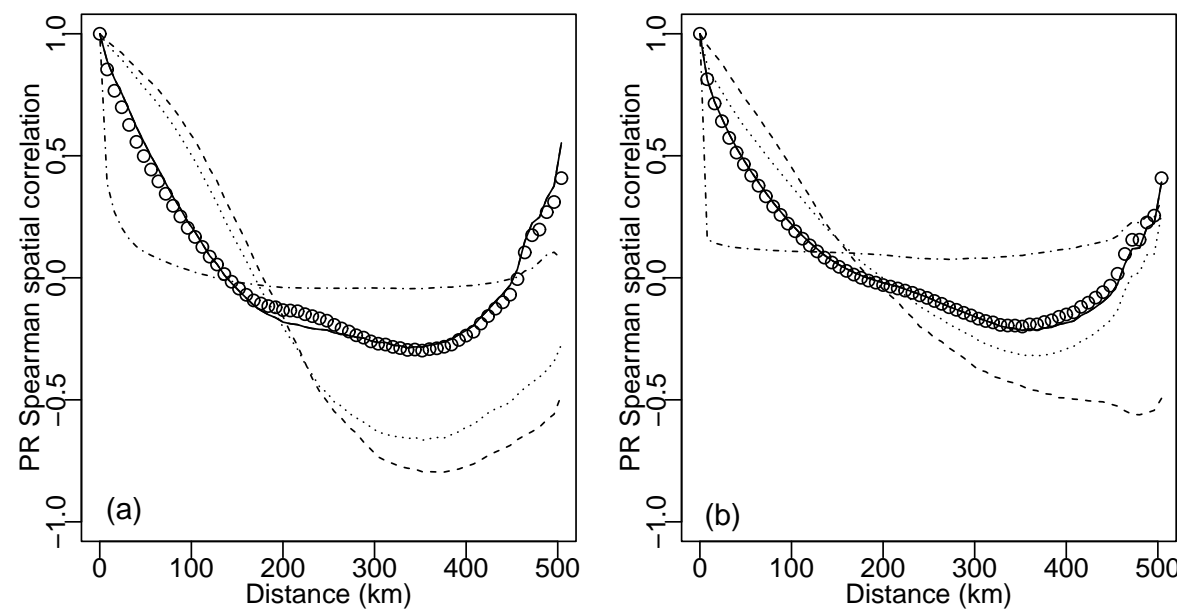

Figure 5. Correlograms in winter over the evaluation period for (a) temperature at $2 \mathrm{~m}$; (b) precipitation, from SAFRAN (circles); ERA-I (dashed); 1d-BC (dotted); 2d-BC (dashed-dotted); 1506d-BC (T2 or PR, long dashed); 3012d-BC (solid line). Note that results of the 1506d(long dashed) and $3012 \mathrm{~d}-\mathrm{R}^{2} \mathrm{D}^{2}$ (solid line) versions are the same and are therefore superimposed. 

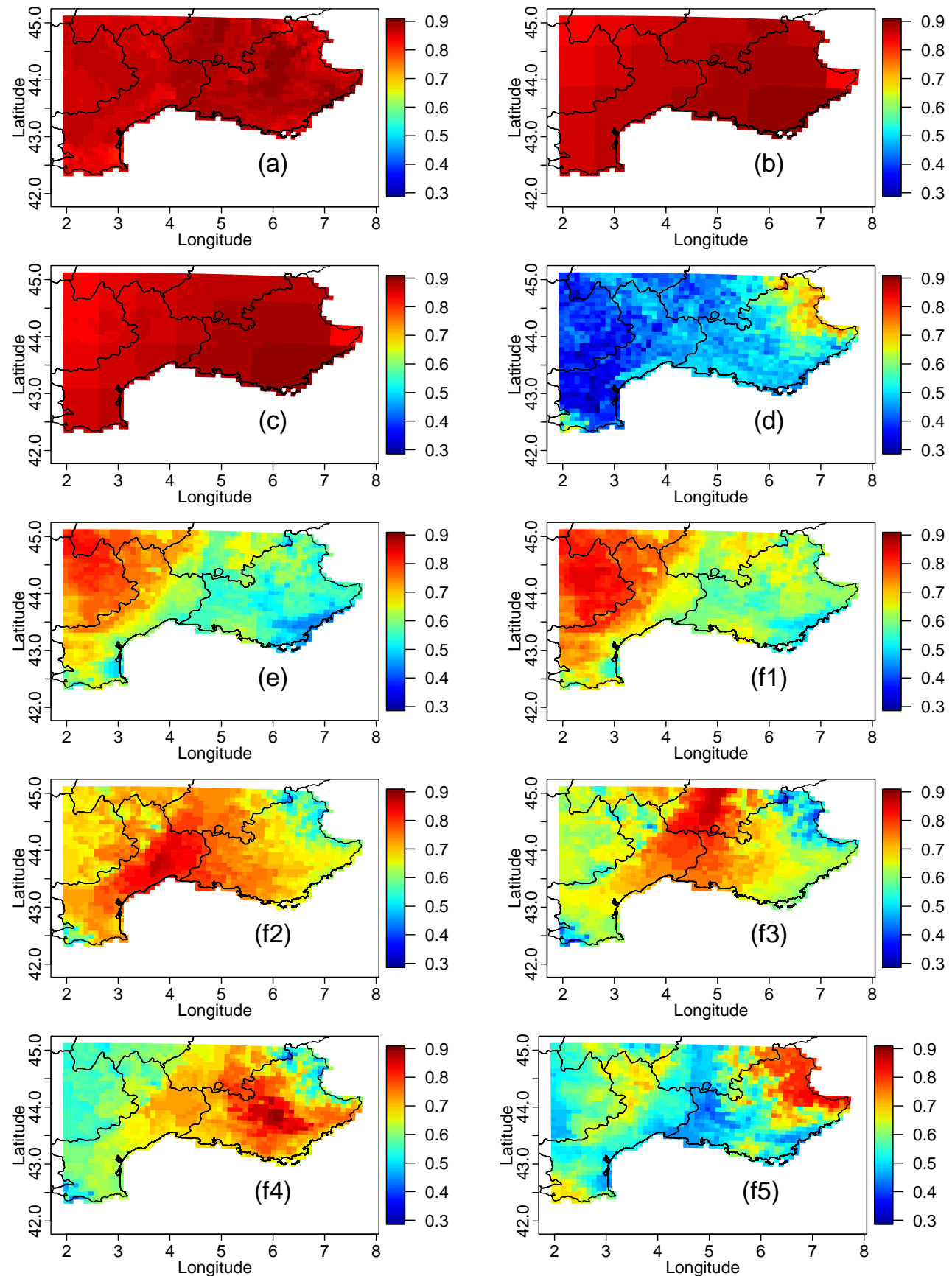

Figure 6. Maps of lag-1 day temperature auto-correlations in winter over the evaluation period for (a) SAFRAN; (b) ERA-I; (c) 1d$\mathrm{BC}$; (d) $2 \mathrm{~d}-\mathrm{R}^{2} \mathrm{D}^{2}$ (with PR as ref.dim. for each grid cell); (e) $1506 \mathrm{~d}-\mathrm{R}^{2} \mathrm{D}^{2}$; (f1-5) $3012 \mathrm{~d}-\mathrm{R}^{2} \mathrm{D}^{2}$ with five different reference temperature locations.

stand how strong those modifications are, depending on the $\mathrm{R}^{2} \mathrm{D}^{2}$ version. Hence, Figs. 6 and 7 display, for each dataset, the 1-day lag auto-correlation maps over the evaluation period for T2 and PR, respectively. For temperature, the ERA-I data (Fig. 6b) have high auto-correlation values between 0.8 and 0.9 in agreement with SAFRAN data (Fig. 6a), although the spatial structure is different (not highlighted here). Since the univariate CDF-t method preserves the rank sequence, the $1 \mathrm{~d}-\mathrm{BC}$ results (Fig. 6c) have similar auto-correlations. However, the other results (2d, 1506d and 3012d) deeply change the ERA-I auto-correlation values, with a strong reduction from the $2 \mathrm{~d}-\mathrm{BC}$ results (Fig. 6d). For the 3012d$\mathrm{R}^{2} \mathrm{D}^{2}$ version, the auto-correlations depend on the statistical dimension serving as reference. Therefore, five illustrations 

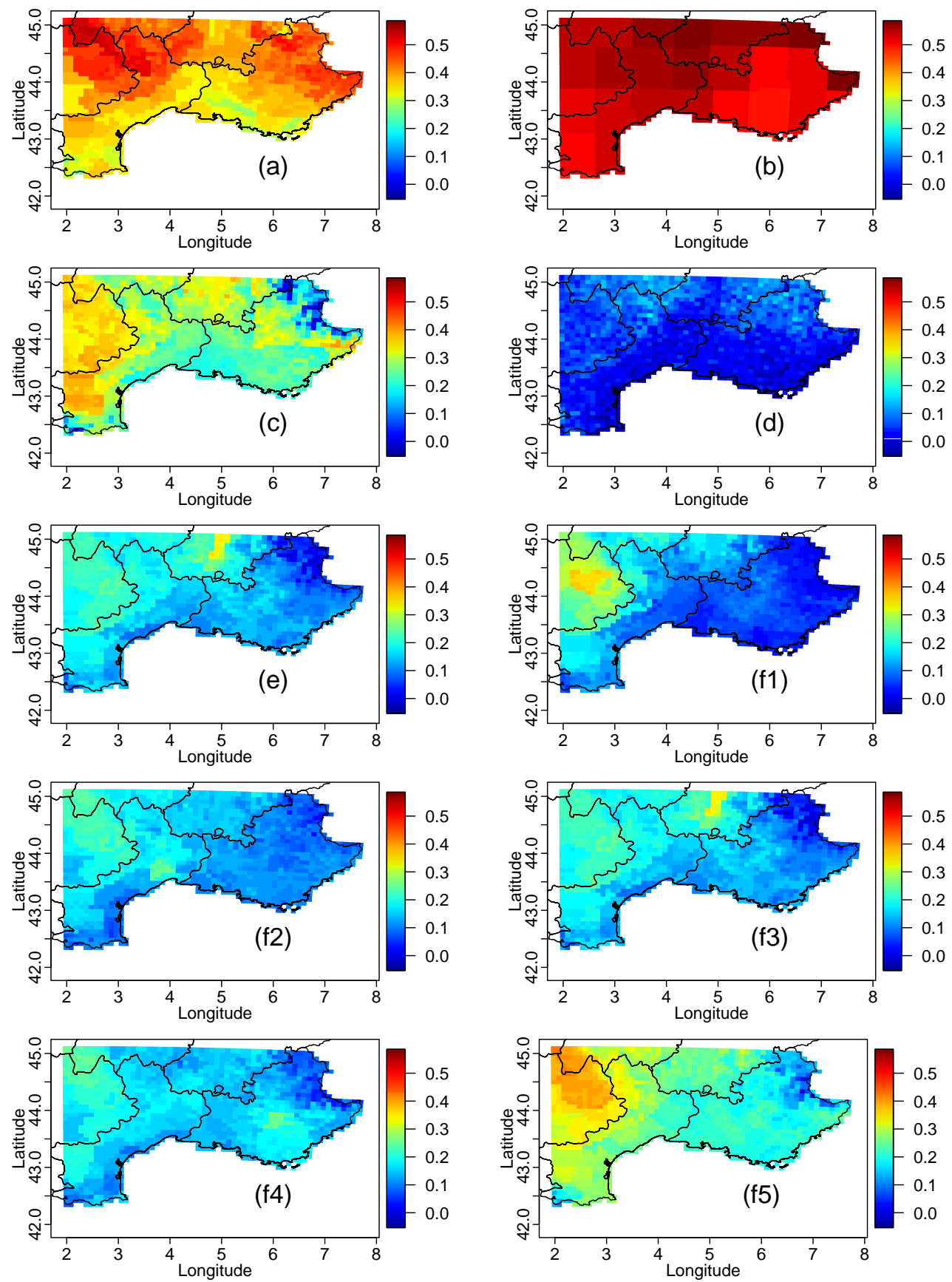

Figure 7. Same as Fig. 6 but for precipitation.

are provided in panels $6 \mathrm{f} 1-\mathrm{f} 5$ obtained from five reference dimensions, here corresponding to temperature at five locations. Interestingly, those five locations roughly correspond to the center of the red zones visible in panels Fig. 6f1-f5. Indeed, as the reference dimension preserves the rank sequence of the $1 \mathrm{~d}-\mathrm{BC}$ - and therefore of the model data to be corrected - the same auto-correlation values are found at this specific location. The obtained correlation is somehow also reproduced on a neighborhood more or less ex- tended around this location, and rapidly decreases out of this neighborhood. For precipitation (Fig. 7), the same behavior is present although less pronounced. Moreover, the ERA-I auto-correlation results (Fig. 6b) are not in agreement with SAFRAN (Fig. 6a) anymore, and the 1d-BC results (Fig. 6c) appear quite different from ERA-I. The changes in behavior of the different $\mathrm{BC}$ results come from the precipitation occurrences that are modified both in frequency and in the structure of their sequence (e.g., spells). This is not shown 

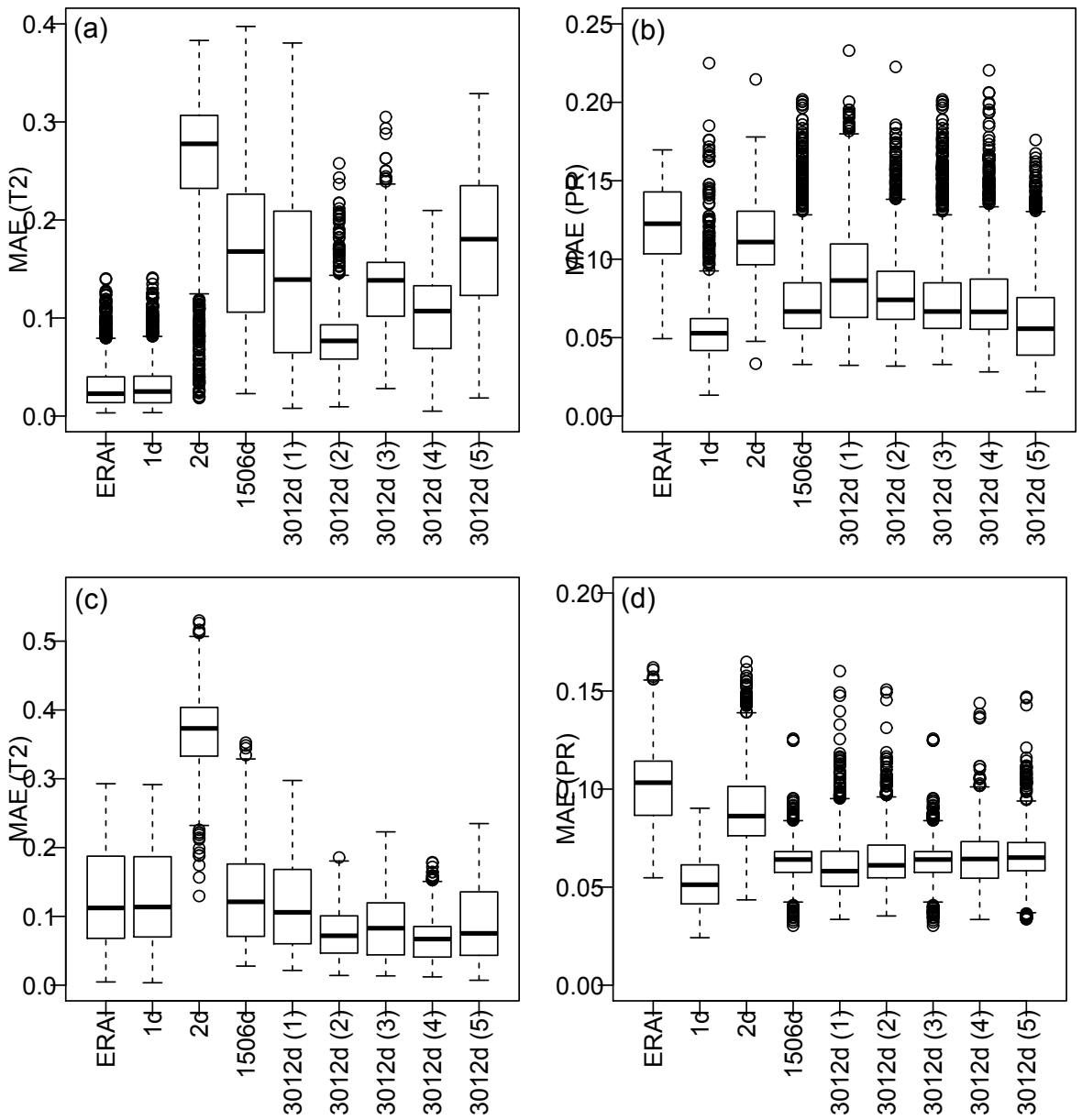

Figure 8. Box plots of the mean absolute error (MAE) values calculated on lag-1 to lag-7 day Pearson correlations for: ERA-I; 1d-BC; 2d-BC; 1506d-BC of T2 or PR (example for first reference variable); 3012d-BC with five different reference temperature locations. (a, c) for 2 m-temperature; $(\mathbf{b}, \mathbf{d})$ for precipitation; $(\mathbf{a}, \mathbf{b})$ winter; $(\mathbf{c}, \mathbf{d})$ summer.

here to constrain this article to a reasonable size but maps of wet and dry spell mean lengths as well as maps of probability of dry day given that the previous one is wet, and the other way around, are provided in the Supplement for both winter and summer. Nevertheless, in order to have a larger view on the temporal correlation of the different datasets, the mean absolute error (hereafter referred to as MAE) with respect to SAFRAN was computed over the evaluation period for each grid cell and physical variable, based on the first seven autocorrelation values:

$\mathrm{MAE}=\sum_{n=1}^{7} \mid \rho_{n}(D)-\rho_{n}($ SAFRAN $) \mid$,

where $\rho_{n}(D)$ is the $n$-day lag auto-correlation value of the dataset $D$. The resulting values are presented via box plots summarizing the spatial variability of the MAE - in Fig. 8, and via maps as Supplement. For temperature (left panels of Fig. 8), except for the 2d-BC results that show a degradation of the MAE values compared to those from ERA-I or
1d-BC for both seasons, the conclusions are not exactly the same in winter and in summer. In winter, the MAE results from the 1506d- and 3012d-BC versions are of lower quality (i.e., higher MAE values) than those from ERA-I. This is not the case in summer where those versions present equivalent or even better (i.e., smaller) MAE values. For precipitation, however, winter and summer results are consistent: all tested BC methods generally improve the ERA-I MAEs - although only slightly for $2 d-R^{2} D^{2}-$ and the $1506 \mathrm{~d}$ - and $3012 d-R^{2} D^{2}$ MAE are relatively close to those from the $1 d-$ $\mathrm{BC}$ that presents the best (i.e., smallest) MAE values.

\section{Bias correction of RCM simulations}

\subsection{GCM/RCM runs and scenario}

For illustration purposes, in order to evaluate and compare the different BC methods when applied to regional climate simulations over a historical period and in a future climate 
change context, two RCMs driven by the same GCM are used to provide simulations to be corrected. Those RCMs are (i) the "Weather Research and Forecasting" (WRF) regional climate model (Skamarock et al., 2008) developed by the National Center for Atmospheric Research and (ii) the "Rossby Centre regional Atmospheric" model (RCA4; Samuelsson et al., 2011). Both RCMs provide daily simulations at a $0.11^{\circ} \times 0.11^{\circ}$ spatial resolution over the European domain of the Coordinated Regional Climate Downscaling Experiment (CORDEX; Giorgi et al., 2009; Jacob et al., 2014), and were forced by the "Institut Pierre Simon Laplace" (IPSL) global climate model (Marti et al., 2010; Dufresne et al., 2013) with a "historical" 1950-2005 run, as well as for the 2006-2100 time period under a scenario of representative concentration pathway associated with a radiative forcing of $+8.5 \mathrm{~W} \mathrm{~m}^{2}$ (RCP8.5) in the year 2100 with respect to the preindustrial period (IPCC, 2013). The calibration of the different BC methods is made over the SAFRAN 1980-2009 time period, and for the same winter and summer seasons as previously. The corrections of the WRF and RCA4 simulations are then performed over 1980-2009 and 2071-2100, and only with 1d-CDF-t, $2 d-R^{2} D^{2}$ (for T2 and PR together but for each of the 1506 grid cell separately) and $3012 \mathrm{~d}-\mathrm{R}^{2} \mathrm{D}^{2}$. The $1506 \mathrm{~d}-$ $\mathrm{BC}$ version (either on $\mathrm{T} 2$ or $\mathrm{PR}$ ) was not performed in this section since, in the previous one, it provided either equivalent or lower quality results than the $3012 \mathrm{~d}-\mathrm{R}^{2} \mathrm{D}^{2}$ version. In the following, results are given for the WRF model in winter but the WRF summer and RCA4 winter and summer results are provided as Supplement.

\subsection{Historical evaluations and changes from historical to future climate simulations}

This subsection contains a short evaluation of the BC methods applied to the RCM simulations over the 1980-2009 historical period, as well as an illustration of how the tested BC methods behave and differ from each other in a climate change context, both in terms of inter-variable and inter-site dependencies. As an objective of this sub-section is to evaluate the changes from the historical (1980-2009) to the future (2071-2100) time periods, in order to save space, the evaluations of the BC methods applied to the RCM simulations are performed directly over the whole historical period (1980-2009), without cross-validation. Nevertheless, when applying the same cross-validation exercise as was done with ERA-I in Sect. 5, the conclusions were exactly the same with RCM data (not shown). First, for each dataset, the intervariable correlation between $\mathrm{T} 2$ and $\mathrm{PR}$ in winter is calculated for each grid cell for both the historical and future time period. The resulting maps are presented in the left panels of Fig. 9. Similarly to the BC of the ERA-I reanalyses, although the inter-variable correlations from WRF and its 1d$\mathrm{BC}$ are quite distinct from the reference ones, the $2 \mathrm{~d}-$ and $3012 d-R^{2} D^{2}$ versions (Fig. 9e and g, respectively) provide the same maps as that from SAFRAN (Fig. 9i), confirm- ing their performance also on RCM simulations. However, the $2 \mathrm{~d}$-version does not do so well from the spatial perspective, as illustrated in Fig. 10 showing the temperature and precipitation correlograms. When driven by the "opposite" variable (i.e., T2 for PR correlograms and PR for T2 correlograms), the $2 \mathrm{~d}-\mathrm{BC}$ correlograms are away from both SAFRAN and RCM data, with a strong fall of correlation as soon as the very short distances (a few $\mathrm{km}$ ) and a flat behavior after. As for the 3012d-BC of WRF, its correlogram nicely fits the empirical correlations calculated from SAFRAN for both variables. Regarding the RCM future climate simulations and their bias corrections, right panels of Fig. 9 show the changes (i.e., future - present) of the inter-variable correlations. The 1d-CDF-t method smoothes the RCM changes but preserves their structure, while, as expected, the $2 \mathrm{~d}$ - and 3012d-BC versions do not present strong changes and therefore tend to provide an inter-variable correlation structure close to that of the SAFRAN data. For the changes in the temperature correlograms (Fig. 10a), the RCM simulations do not present much evolutions from the historical period to 2071-2100, and therefore the 1d-BC does the same. Moreover, neither the $2 \mathrm{~d}-\mathrm{BC}$ nor the $3012 \mathrm{~d}$-version show major changes and so the two versions are consistent with the raw simulations in terms of changes. For precipitation (Fig. 10b), the RCM simulations (solid and dashed black lines) do see some changes in the spatial dependence, and therefore, so does the 1d-BC (green lines). Interestingly, the 3012d-BC (red and orange, superimposed) also captures some changes, although slightly less pronounced. This means that 3012d$\mathrm{R}^{2} \mathrm{D}^{2}$ allows a change (from historical to future) in the intersite dependence structure that is consistent with the change provided by the RCM.

\section{Conclusions and discussion}

\subsection{Conclusions}

A new multivariate bias correction approach was proposed, allowing to correct not only the marginal (univariate) distributions of the climate variables of interest but also the statistical dependences between the variables, as well as the dependences between the different locations over a given geographical domain. This approach relies on the previously developed "Empirical Copula - Bias Correction" (EC-BC, Vrac and Friederichs, 2015) method, whose all dependence structures - inter-variable, inter-site and overall temporal were taken from reference data and exactly reproduced by the EC-BC correction. The suggested BC approach is also based on a rank resampling to adjust the copula functions and therefore the dependences of the climate simulations, but this $\mathrm{R}^{2} \mathrm{D}^{2}$ method relaxes the EC-BC temporal constraint to let the climate model of interest express its temporal dynamics. Indeed, $\mathrm{R}^{2} \mathrm{D}^{2}$ is based on the assumption that the inter-site and inter-variable copula (dependence) functions 

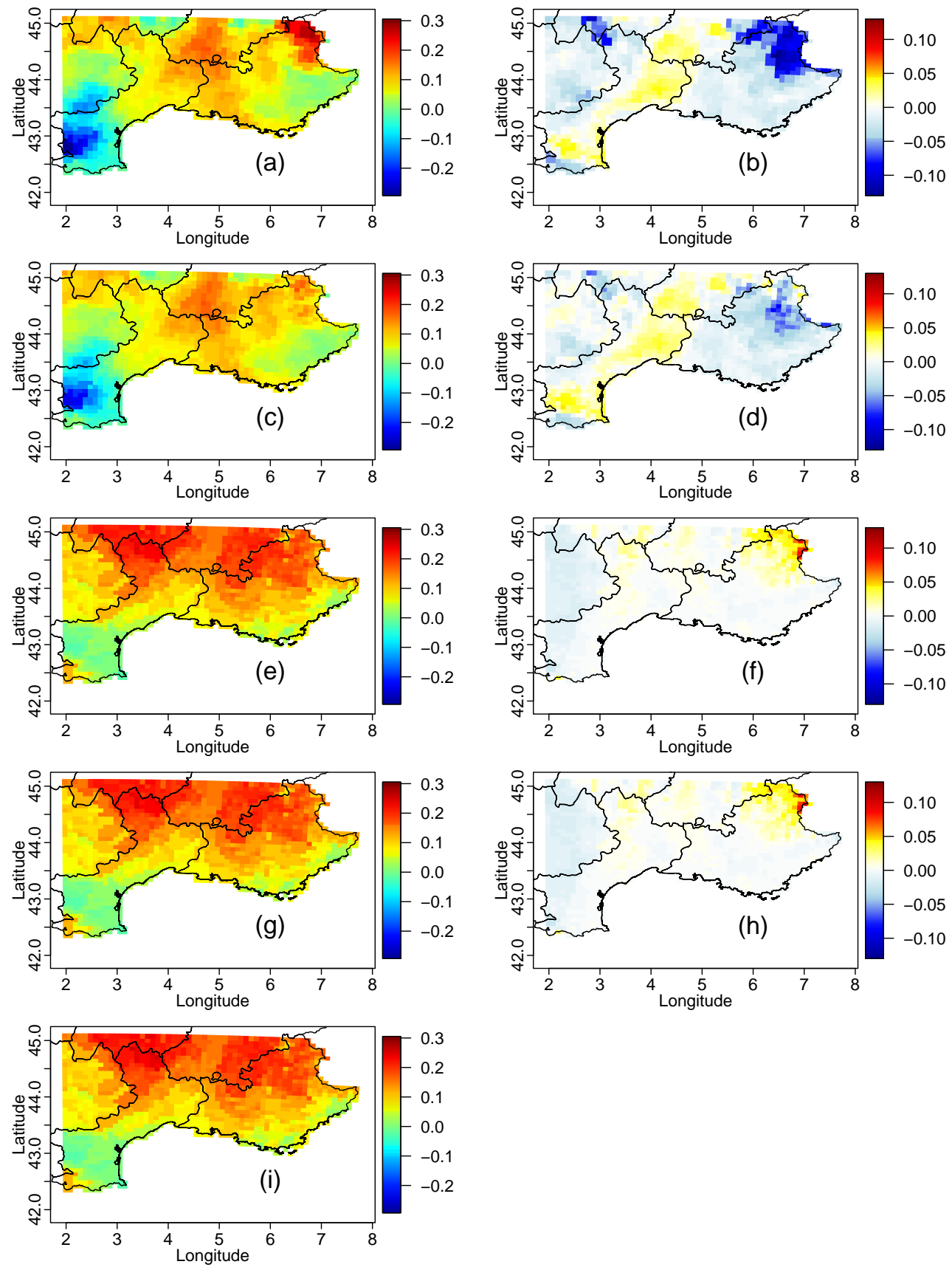

Figure 9. (left column) Inter-variable Pearson correlations between T2 and PR in winter for each grid cell and (right column) changes in intervariable Pearson correlations from the historical period to the 2071-2100 period; (a-b) for the WRF RCM; (c-d) for its 1d- bias correction with CDFt; (e-f) for its $2 \mathrm{~d}-\mathrm{R}^{2} \mathrm{D}^{2}$ correction; $(\mathbf{g}-\mathbf{h})$ for its $3012 \mathrm{~d}-\mathrm{R}^{2} \mathrm{D}^{2}$ correction. Panel (i) corresponds to the correlations between $\mathrm{T} 2$ and PR for the SAFRAN reference data over the historical period.

are imposed by physical constraints over the region of interest and are therefore stable in time. Therefore, their dependence structures can be extracted and reconstructed from reference historical data. However, $\mathrm{R}^{2} \mathrm{D}^{2}$ is explicitly designed to partially respect the changes in the climate model (e.g., from historical to future periods) in terms of tempo- ral (rank) properties. Since these evolutions can be distinct for different physical variables and/or grid cell, $\mathrm{R}^{2} \mathrm{D}^{2}$ generates multiple bias corrected scenarios, which can be considered as a stochasticity describing the possible variability in the different rank chronologies. As such, $\mathrm{R}^{2} \mathrm{D}^{2}$ can be seen as a method that is halfway between a multivariate correc- 

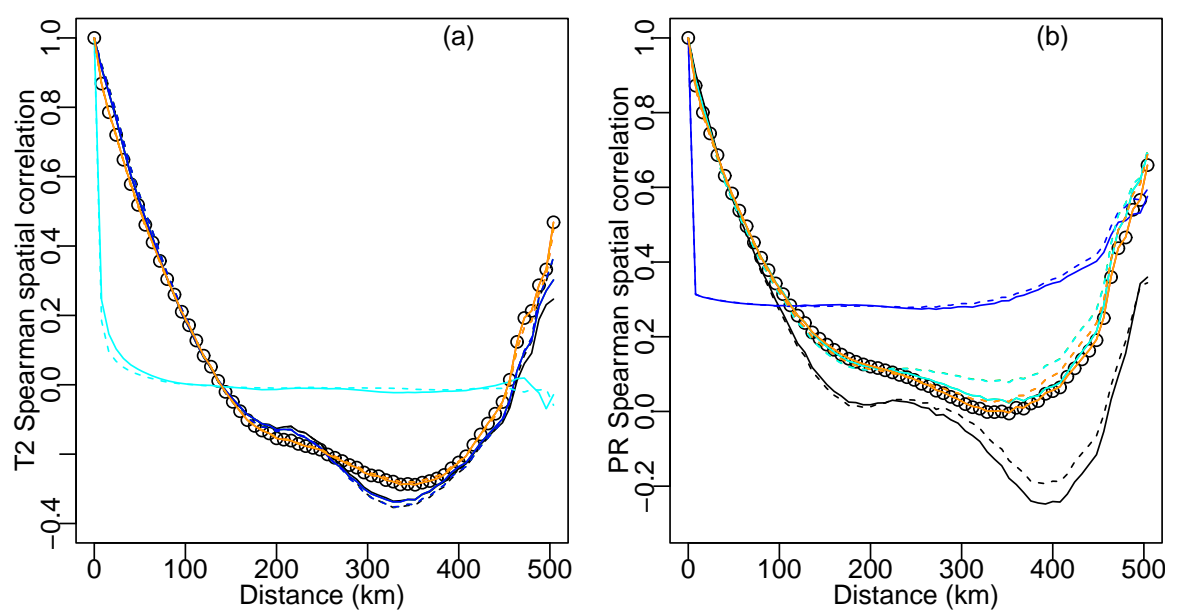

Figure 10. Spatial correlograms of temperature (a) and precipitation (b) in winter computed from daily areal mean-removed data. Correlations from SAFRAN are in circles; those from the WRF RCM are in black lines; $1 \mathrm{~d}-\mathrm{BC}$ in green; $2 \mathrm{~d}-\mathrm{R}^{2} \mathrm{D}^{2}$ driven by temperature in blue; $2 \mathrm{~d}-\mathrm{R}^{2} \mathrm{D}^{2}$ driven by precipitation in cyan; $3012 \mathrm{~d}-\mathrm{R}^{2} \mathrm{D}^{2}$ driven by temperature at a given location in red; $3012 \mathrm{~d}-\mathrm{R}^{2} \mathrm{D}^{2}$ driven by precipitation at the same location in orange. Solid lines indicate results for the historical period and dashed lines for the 2071-2100 period. Note that for temperature results (a), green and blue lines are superimposed. For precipitation (b), green and cyan are superimposed. Red and orange lines are always superimposed for both (a) and (b).

tion method and a conditional multivariate stochastic weather generator. The assumption of stability of the copula function - which can hence be reproduced from the reference data allows us to apply the multivariate bias correction in a highdimensional context and at a reasonable computational cost. For example, the dataset generated by $3012 \mathrm{~d}-\mathrm{R}^{2} \mathrm{D}^{2}$ and analyzed in Sect. 5 (2734 winter days to be corrected for temperature and precipitation over 1506 grid cell) was obtained on a regular laptop computer with a $2.2 \mathrm{GHz}$ Intel Core i7 processor and a 8 Go $1600 \mathrm{MHz}$ DDR3 memory. On this computer, for each of the 1506 grid cell, the application of CDF-t (i.e., calibration and correction) takes about $0.05 \mathrm{~s}$ for temperature and $0.01 \mathrm{~s}$ for precipitation. Then, for one selected reference dimension, in the 3012-dimensional context, each application of the steps $2-4$ of the $\mathrm{R}^{2} \mathrm{D}^{2}$ algorithm presented in Sect. 3.3 takes about $15 \mathrm{~s}$. Consequently, the whole computation time of the $3012 \mathrm{~d}-\mathrm{R}^{2} \mathrm{D}^{2}$ version with 10 reference dimensions (and therefore 10 multivariate $\mathrm{BC}$ scenarios) took: $1506 \times(0.05+0.01)=90.4 \mathrm{~s}($ for the univariate BC, step 1$)+$ $10 \times 15=150$ s (for the 10 iterations of the steps $2-4$ ), summing to about $240 \mathrm{~s}=4 \mathrm{~min}$.

$\mathrm{R}^{2} \mathrm{D}^{2}$ was first applied to adjust temperature and precipitation time series from ERA-Interim reanalyses (Dee et al., 2011) with respect to the SAFRAN dataset (Quintana-Segui et al., 2008) under a temporal cross-validation framework on 1506 locations. Different configurations of $\mathrm{R}^{2} \mathrm{D}^{2}$ were compared: a bivariate one $\left(2 \mathrm{~d}-\mathrm{R}^{2} \mathrm{D}^{2}\right)$ applied to jointly adjust temperature and precipitation but separately for each grid cell, a 1506-dimensional version (1506d- $\left.\mathrm{R}^{2} \mathrm{D}^{2}\right)$ applied jointly on the 1506 grid cell but separately for temperature and precipitation and a 3012-dimensional one (3012d-
$\mathrm{R}^{2} \mathrm{D}^{2}$ ) where the two variables were jointly corrected over the 1506 grid cell. Those different versions were also compared to the univariate CDF-t bias correction method (e.g., Vrac et al., 2012) and to the raw ERA-I data. The results indicate that the $1 \mathrm{~d}-\mathrm{BC}$ by CDF-t generally reproduces the statistical dependence properties of the data to be corrected, from both the inter-variable, inter-site and temporal perspectives. Moreover, by construction, if $2 \mathrm{~d}-\mathrm{R}^{2} \mathrm{D}^{2}$ greatly improves the temperature-precipitation relationship, it does not do so well for inter-site dependences. This is the other way around for the $1506 d-R^{2} D^{2}$ that shows satisfying inter-site dependence reconstructions but disregards the inter-variable relationship. However, the $3012 \mathrm{~d}-\mathrm{R}^{2} \mathrm{D}^{2}$ performs well for both the intervariable and inter-site property corrections. Regarding the temporal properties, except for the winter temperature with the tested datasets, most $\mathrm{BC}$ versions tend to provide autocorrelation getting slightly closer to SAFRAN's. However, it is worth keeping in mind that none of the multivariate BC versions were designed to adjust the temporal properties.

The different $\mathrm{BC}$ versions were then also tested and compared on climate simulations from the WRF and RCA4 regional climate models (RCMs) over the 1980-2009 historical period as well as the 2071-2100 future time period. The 2071-2100 bias corrections was not made to evaluate the methods (since no reference data are available for the future) but rather to illustrate how the different multivariate $R^{2} D^{2}$ versions behave in a climate change context. The evaluations over the historical period confirmed the results obtained on ERA-I, indicating a robustness of $\mathrm{R}^{2} \mathrm{D}^{2}$ to the dataset to be corrected. 


\subsection{Future work and discussion}

The possible future developments of this work are both methodological and applied. First, as stated earlier, the variability/stochasticity introduced in the actual $\mathrm{R}^{2} \mathrm{D}^{2}$ version refers only to the timing of the events and does not perturb at all the corrected marginal distributions, neither the spatial dependence between sites and/or variables. More stochasticity could also be included into those properties. For example, the inference of a parametric modeling of copulas (or more generally of the dependence structures) would provide parameters generally associated with some uncertainty (or confidence intervals). Resampling those parameters based on this uncertainty would then allow us to generate "perturbed" copulas consistent with each other, and therefore multivariate corrections that are stochastic in their dependences.

Moreover, based on the results presented in this study, the assumption of conservation of the dependence structure sounds reasonable for the inter-site aspects (Fig. 10) but a bit more questionable for the inter-variable aspects, since the tested RCM shows some evolution of the inter-variable correlation in the future (Fig. 9). A generalization of this type of analysis to many more climate models is therefore needed to assess if the dependence preservation hypothesis is robust. This point can be reformulated as a practical question for multivariate $\mathrm{BC}$ developments: should the (inter-variable and/or inter-site) dependence structures evolve from calibration to projection periods? Due to the relative youth of the multivariate $\mathrm{BC}$ methods, this is still an open question in the literature that should be further investigated and debated.

Furthermore, the $\mathrm{R}^{2} \mathrm{D}^{2}$ method only partially preserves the temporal properties of the simulations to be corrected, and all multivariate $\mathrm{BC}$ methods necessarily modify the temporal structure and rank chronology of the simulations. If this is indirect for most of them (i.e., when accounting only for inter-site or inter-variable structures), some authors tried specifically to tackle the question of the temporal properties adjustment, such as Johnson and Sharma (2012) with a nesting 1d-BC model working across multiple timescales, Mehrotra and Sharma (2015) including inter-site dependence or Mehrotra and Sharma (2016) including multiple meteorological variables. However, no general comparison of the pros and cons of the two approaches has been performed and any BC method for both inter-site, inter-variable and temporal properties will necessarily consist of a trade-off between the temporal modifications brought by the multivariate adjustment and the correction of the temporal aspects, while respecting their changes from one time period to another.

More generally, there is not yet a complete intercomparison of the multivariate bias adjustment methods. As the need for such multivariate methods becomes crucial for many impact studies, intercomparison exercises are now essential to evaluate the various existing methodologies and to make distinctions, not only between "marginals/dependence" and "successive conditional" correction approaches for example but also between different methods and assumptions within each approach. If such an intercomparison study has to be performed first from the climate point of view (i.e., in terms of quality of the corrected climate variables and their various properties), it should also be conducted from the perspective of some specific impacts and impact models, trying to understand how the quality of the bias adjusted simulations transfer into the often non-linear impact model outputs. To do so, applying a high-dimensional $\mathrm{R}^{2} \mathrm{D}^{2}$ (and other methods) to various CMIP5 (and upcoming CMIP6) GCM simulations or to various CORDEX RCM runs would generate useful large datasets of multivariate bias corrected climate simulations. From the purely climatic point of view, those datasets would provide a corrected ensemble to conduct climate change studies, such as related to detection and attribution questions (e.g., Yiou et al., 2017), to the evolution in risks of compound events (e.g., Bevacqua et al., 2017) or more generally related to understanding of climate changes. From the societal and/or environmental point of view, those ensembles of multivariate corrected simulations would allow us to investigate how the correction of the dependence structures might modify the impacts of climate change. This question is quite large and concerns many domains, such as hydrology, agronomy, ecology, etc., and can have major consequences on adaptation and mitigation strategies.

Finally, the selection of an "optimal" reference dimension, or at least some preferential ones, is certainly a necessary future step. However, the notion of optimality here may depend on the context of the correction and on the subsequent use of the multivariate bias-corrected data. However, simple selection methods can be imagined. For example, a logical choice can be to select the dimension for which the temporal dynamics of the model to be corrected is the most similar to that of the observations over the calibration period. In such a case, that could correspond to the dimension for which the Spearman rank correlation (or an auto-correlation value) is the closest to that of the reference (observational) data. Of course, other selections are possible but this question is left for future work. In the same idea, we could also consider a "multivariate" reference vector. For example, instead of relying on a univariate reference dimension, the latter can be a couple (or more generally a $n$-dimensional vector) of dimensions. This would then ensure that the dependence structure linking those dimensions would be exactly that of the initial model and therefore "preserved" (i.e., not corrected). Another natural extension would also be to replace the univariate or multivariate "reference dimension" time series (used to condition the rank resampling in $\mathrm{R}^{2} \mathrm{D}^{2}$ ) by physical indices, such as NAO or ENSO indices, coming from the climate model to correct. Hence, by such an approach, $\mathrm{R}^{2} \mathrm{D}^{2}$ would be applied in a conditional process-oriented $\mathrm{BC}$ framework. Indeed, if the present study focused on the methodological aspects of the multivariate bias correction, it is worth keeping in mind that any application of a BC method should be performed with some physically based motivations: depending 
on their intrinsic skills to model specific features, some climate simulations cannot sensibly be corrected, especially in climate change context where artifacts of bias correction may appear while not visible in present climate evaluations (e.g., Maraun et al., 2017). So the development of BC methodologies allowing one to include some physics in the adjustment procedure is an important perspective of research, in order to have $\mathrm{BC}$ approaches not used as black boxes while they should be a support to increase the realism of the climate simulations based on physical knowledge.
Data availability. ERA-Interim temperature and precipitation datasets can be accessed through the ECMWF website at https://www.ecmwf.int/en/forecasts/datasets/archive-datasets/ reanalysis-datasets/era-interim/ (Dee et al., 2011). SAFRAN temperature and precipitation datasets can be obtained on demand from Meteo-France (https://donneespubliques.meteofrance.fr/ ?fond=produit\&id_produit $=230 \&$ id_rubrique $=40, \quad$ in French; Quintan-Segui et al., 2008). RCM simulations used in this study can be downloaded from ESGF nodes, more information from https://www.euro-cordex.net/060378/index.php.en (Jacob et al., 2014). 


\section{Appendix A: Some more mathematical descriptions of the $R^{2} D^{2}$ bias correction method}

The multivariate $\mathrm{BC}$ method is applied to $P$ statistical dimensions. Those dimensions encompass several physical variables at several grid cell. For example, if there are $V$ physical variables at each of the $S$ grid cell, then $P=V \times S$. Each dimension is observed or simulated over $N$ time steps, and in the following $V_{p}^{A}(t)$ is the value of the dimension $p$ from the dataset $A$ (reference, raw or corrected simulations) at time $t$.

The $\mathrm{R}^{2} \mathrm{D}^{2}$ method consists of the following steps:

1. Apply separate univariate $\mathrm{BC}$ to each dimension. We obtain $P$ univariate time series of $N$ values: $\left\{\left(V_{1}^{1 \mathrm{dBC}}(1), \ldots, V_{1}^{1 \mathrm{dBC}}(N)\right), \ldots,\left(V_{P}^{1 \mathrm{dBC}}(1), \ldots\right.\right.$, $\left.\left.V_{P}^{1 \mathrm{dBC}}(N)\right)\right\}$;

2. Compute the time series of ranks for each 1d-bias corrected dimension $p$ mong $\left(V_{p}^{1 \mathrm{dBC}}(1), \ldots, V_{p}^{1 \mathrm{dBC}}(N)\right)$. For example, for dimension $p$, we compute $\left(\operatorname{rank}\left(V_{p}^{1 \mathrm{dBC}}(1)\right), \ldots, \quad \operatorname{rank}\left(V_{p}^{1 \mathrm{dBC}}(N)\right)\right)$ that will be denoted as $\left(r_{p}^{1 \mathrm{dBC}}(1), \ldots, r_{p}^{1 \mathrm{dBC}}(N)\right)$. Therefore, for each time $t$, we have a $P$-dimensional vector of ranks: $\mathbf{R}^{1 \mathrm{dBC}}(t)=\left(r_{1}^{1 \mathrm{dBC}}(t), \ldots, r_{P}^{1 \mathrm{dBC}}(t)\right) ;$

3. Compute the time series of ranks for each dimension $p$ among $\left(V_{p}^{\mathrm{ref}}(1), \ldots, V_{p}^{\mathrm{ref}}(N)\right)$ in the reference (calibration) dataset. For example, for dimension $p$, we compute $\left(\operatorname{rank}\left(V_{p}^{\operatorname{ref}}(1)\right), \ldots, \operatorname{rank}\left(V_{p}^{\operatorname{ref}}(N)\right)\right)$ that will be denoted as $\left.r_{p}^{\mathrm{ref}}(1), \ldots, r_{p}^{\mathrm{ref}}(N)\right)$. Therefore, for each time $t$, we have a $P$-dimensional vector of ranks: $\mathbf{R}^{\text {ref }}(t)=$ $\left(r_{1}^{\mathrm{ref}}(t), \ldots, r_{P}^{\mathrm{ref}}(t)\right)$
4. Choose one dimension $p$ (e.g., $p=1$ ) and $\left(V_{p}^{1 \mathrm{dBC}}(1), \ldots, V_{p}^{1 \mathrm{dBC}}(N)\right)$ as the reference dimension and sequence. Then, for each time $t$ from 1 to $N$ in the projection period:

(a) Find $t^{*}$ in the calibration period such that $r_{p}^{1 \mathrm{dBC}}(t)=r_{p}^{\mathrm{ref}}\left(t^{*}\right)$ and therefore deduce $\mathbf{R}^{\mathrm{ref}}\left(t^{*}\right)=$ $\left(r_{1}^{\mathrm{ref}}\left(t^{*}\right), \ldots, r_{P}^{\mathrm{ref}}\left(t^{*}\right)\right)$;

(b) For time $t$ in the projection period, impose that the $P$-dimensional vector of ranks is $\mathbf{R}^{\mathrm{PdBC}}(t)=$ $\left(r_{1}^{\mathrm{ref}}\left(t^{*}\right), \ldots, r_{p}^{1 \mathrm{dBC}}(t), \ldots, r_{P}^{\mathrm{ref}}\left(t^{*}\right)\right)$;

(c) For all dimensions $d \neq p$, find the time step $t_{d}$ such that $r_{d}^{\mathrm{ref}}\left(t^{*}\right)=V_{d}^{1 \mathrm{dBC}}\left(t_{d}\right)$. Then, define the $P$-dimensional BC vector at time $t$ as $\mathrm{MBC}(t)=$ $\left(V_{1}^{1 \mathrm{dBC}}\left(t_{1}\right), \ldots, V_{p}^{1 \mathrm{dBC}}(t), \ldots, V_{P}^{1 \mathrm{dBC}}\left(t_{P}\right)\right)$. Thus, $\mathrm{MBC}=\{\operatorname{MBC}(t=1), \ldots, \operatorname{MBC}(t=N)\}$ gathers the $N P$-dimensional vectors. In other words, MBC is a $P$-dimensional time series of length $N$ and contains the multivariate bias corrected data via $\mathrm{R}^{2} \mathrm{D}^{2}$ with dimension $p$ as reference dimension;

5. Repeat steps $4(\mathrm{a}-\mathrm{c})$ for all dimensions until $P$. This generates $\mathrm{MBC}_{\text {all }}$, which gathers $P$ objects $\mathrm{MBC}$ (one per dimension as reference for the shuffling): $\mathrm{MBC}_{\mathrm{all}}=(\mathrm{MBC}($ ref.dim. $=1), \ldots, \mathrm{MBC}($ ref.dim. $=$ $P))$. 


\section{The Supplement related to this article is available online at https://doi.org/10.5194/hess-22-3175-2018- supplement.}

Competing interests. The author declares that he has no conflict of interest.

Acknowledgements. This work has been partially supported by the ANR-project StaRMIP, the VW-project CE:LLO, the ERA4CS EUPHEME and CoCliServ projects, and the LABEX IPSL project. All computations were made in $\mathrm{R}$. An $\mathrm{R}$ package containing functions for the $\mathrm{R}^{2} \mathrm{D}^{2}$ approach should soon be made available on the CRAN website (http://cran.r-project.org/) or upon request to the author.

Edited by: Florian Pappenberger

Reviewed by: one anonymous referee

\section{References}

Araújo, M. and Rahbek, C.: How Does Climate Change Affect Biodiversity?, Science, 313, 1396-1397, https://doi.org/10.1126/science.1131758, 2006.

Bardossy, A. and Pegram, G.: Multiscale spatial recorrelation of RCM precipitation to produce unbiased climate change scenarios over large areas and small, Water Resour. Res., https://doi.org/10.1029/2011WR011524, 2012.

Berg, P., Feldmann, H., and Panitz, H.-J.: Bias correction of high resolution regional climate model data, J. Hydrol., 448-449, 8092, https://doi.org/10.1016/j.jhydrol.2012.04.026, 2012.

Bevacqua, E., Maraun, D., Hobæk Haff, I., Widmann, M., and Vrac, M.: Multivariate statistical modelling of compound events via pair-copula constructions: analysis of floods in Ravenna (Italy), Hydrol. Earth Syst. Sci., 21, 2701-2723, https://doi.org/10.5194/hess-21-2701-2017, 2017.

Cannon, A.: Multivariate quantile mapping bias correction: An Ndimensional probability density function transform for climate model simulations of multiple variables, Clim. Dynam., 50, 3149, https://doi.org/10.1007/s00382-017-3580-6, 2017.

Christensen, J., Boberg, F., Christensen, O., and Lucas-Picher, P.: On the need for bias correction of regional climate change projections of temperature and precipitation, Geophys. Res. Lett., 35, https://doi.org/10.1029/2008GL035694, 2008.

Clark, M., Gangopadhyay, S., Hay, L., Rajagopalan, B., and Wilby, R.: The Schaake shuffle: A method for reconstructing space-time variability in forecasted precipitation and temperature fields, J. Hydrometeor., 5, 243-262, 2004.

Colette, A., Vautard, R., and Vrac, M.: Regional climate downscaling with prior statistical correction of the global climate forcing, Geophys. Res. Lett., 39, L13707, https://doi.org/10.1029/2012GL052258, 2012.

Dee, D. P., Uppala, S. M., Simmons, A. J., Berrisford, P., Poli, P., Kobayashi, S., Andrae, U., Balmaseda, M. A., Balsamo, G., Bauer, P., Bechtold, P., Beljaars, A. C. M., van de Berg, L., Bidlot, J., Bormann, N., Delsol, C., Dragani, R., Fuentes, M., Geer,
A. J., Haimberger, L., Healy, S. B., Hersbach, H., Hólm, E. V., Isaksen, L., Kållberg, P., Köhler, M., Matricardi, M., McNally, A. P., Monge-Sanz, B. M., Morcrette, J.-J., Park, B.-K., Peubey, C., de Rosnay, P., Tavolato, C., Thépaut, J.-N., and Vitart, F.: The ERA-Interim reanalysis: configuration and performance of the data assimilation system, Q. J. Roy. Meteor. Soc., 137, 553-597, https://doi.org/10.1002/qj.828, 2011 (data available at: https://www.ecmwf.int/en/forecasts/datasets/archive-datasets/ reanalysis-datasets/era-interim/, last access: 1 June 2018).

Dekens, L., Parey, S., Grandjacques, M., and Dacunha-Castelle, D.: Multivariate distribution correction of climate model outputs: A generalization of quantile mapping approaches, Environmetrics, 28, e2454, https://doi.org/10.1002/env.2454, 2017.

Déqué, M.: Frequency of precipitation and temperature extremes over France in an anthropogenic scenario: Model results and statistical correction according to observed values, Global Planet. Change, 57, 16-26, 2007.

Dufresne, J.-L., Foujols, M.-A., Denvil, S., Caubel, A., Marti, O., Aumont, O., Balkanski, Y., Bekki, S., Bellenger, H., Benshila, R., Bony, S., Bopp, L., Braconnot, P., Brockmann, P., Cadule, P., Cheruy, F., Codron, F., Cozic, A., Cugnet, D., de Noblet, N., Duvel, J.-P., Ethé, C., Fairhead, L., Fichefet, T., Flavoni, S., Friedlingstein, P., Grandpeix, J.-Y., Guez, L., Guilyardi, E., Hauglustaine, D., Hourdin, F., Idelkadi, A., Ghattas, J., Joussaume, S., Kageyama, M., Krinner, G., Labetoulle, S., Lahellec, A., Lefebvre, M.-P., Lefevre, F., Levy, C., Li, Z. X., Lloyd, J., Lott, F., Madec, G., Mancip, M., Marchand, M., Masson, S., Meurdesoif, Y., Mignot, J., Musat, I., Parouty, S., Polcher, J., Rio, C., Schulz, M., Swingedouw, D., Szopa, S., Talandier, C., Terray, P., Viovy, N., and Vuichard, N.: Climate change projections using the IPSL-CM5 Earth System Model: from CMIP3 to CMIP5, Clim. Dynam., 40, 2123-2165, 2013.

Giorgi, F., Jones, C., and Asrar, G.: Addressing climate information needs at the regional level: the CORDEX framework, Bull. World Meteorol. Organ., 58, 175-183, 2009.

Haddad, Z. and Rosenfeld, D.: Optimality of empirical z-r relations, Q. J. Roy. Meteor. Soc., 123, 1283-1293, 1997.

IPCC: Climate Change 2013: The Physical Science Basis. Contribution of Working Group I to the Fifth Assessment Report of the Intergovern mental Panel on Climate Change, edited by: Stocker, T. F., Qin, D., Plattner, G.-K., Tignor, M., Allen, S. K., Boschung, J., Nauels, A., Xia, Y., Bex , V., and Midgley, P. M., Cambridge University Press, Cambridge, United Kingdom and New York, NY, USA, 2013.

Jacob, D., Petersen, J., Eggert, B., Alias, A., Christensen, O. B., Bouwer, L. M., Braun, A., Colette, A., Déqué, M., Georgievski, G., Georgopoulou, E., Gobiet, A., Nikulin, G., Haensler, A., Hempelmann, N., Jones, C., Keuler, K., Kovats, S., Kröner, N., Kotlarski, S., Kriegsmann, A., Martin, E., van Meijgaard, E., Moseley, C., Pfeifer, S., Preuschmann, S., Radtke, K., Rechid, D., Rounsevell, M., Samuelsson, P., Somot, S., Soussana, J.F., Teichmann, C., Valentini, R., Vautard, R., and Weber, B.: EURO-CORDEX: New high-resolution climate change projections for European impact research, Reg. Environ. Change, 14 563-578, 2014 (data available at: https://www.euro-cordex.net/ 060378/index.php.en, last access: 1 June 2018).

Johnson, F. and Sharma, A.: A nesting model for bias correction of variability at multiple time scales in general circula- 
tion model precipitation simulations, Water Resour. Res., 48, W01504, https://doi.org/10.1029/2011WR010464, 2012.

Kallache, M., Vrac, M., Naveau, P., and Michelangeli, P.A.: Non-stationary probabilistic downscaling of extreme precipitation, J. Geophys. Res.-Atmos., 116, D05113, https://doi.org/10.1029/2010JD014892, 2011.

Lavaysse, C., Vrac, M., Drobinski, P., Lengaigne, M., and Vischel, T.: Statistical downscaling of the French Mediterranean climate: assessment for present and projection in an anthropogenic scenario, Nat. Hazards Earth Syst. Sci., 12, 651-670, https://doi.org/10.5194/nhess-12-651-2012, 2012. .

Li, Z., Shi, X., and Li, J.: Multisite and multivariate GCM downscaling using a distribution-free shuffle procedure for correlation reconstruction, Climate Res., 72, 141-151, https://doi.org/10.3354/cr01460, 2017.

Mao, G., Vogl, S., Laux, P., Wagner, S., and Kunstmann, H.: Stochastic bias correction of dynamically downscaled precipitation fields for Germany through Copula-based integration of gridded observation data, Hydrol. Earth Syst. Sci., 19, 17871806, https://doi.org/10.5194/hess-19-1787-2015, 2015.

Maraun, D., Shepherd, T., Widmann, M., Zappa, G., Walton, D., Gutierrez, J., Hagemann, S., Richter, I., Soares, P., Hall, A., and Mearns, L.: Towards process informed bias correction of climate change simulations, Nat. Clim. Change, 7, 764-773, https://doi.org/10.1038/nclimate3418, 2017.

Marti, O., Braconnot, P., Dufresne, J., Bellier, J., R., B., Bony, S., Brockmann, P., Cadule, P., Caubel, A., Codron, F., de Noblet, N., Denvil, S., Fairhead, L., Fichefet, T., Foujols, M., Friedlingstein, P., Goosse, H., Grandpeix, J., Guilyardi, E., Hourdin, F., Idelkadi, A., Kageyama, M., Krinner, G., Lévy, C., Madec, G., Mignot, J., Musat, I., Swingedouw, D., and Talandier, C.: Key features of the IPSL ocean atmosphere model and its sensitivity to atmospheric resolution, Clim. Dynam., 34, 1-26, 2010.

Mehrotra, R. and Sharma, A.: Correcting for systematic biases in multiple raw GCM variables across a range of timescales, J. Hydrol., 520, 214-223, https://doi.org/10.1016/j.jhydrol.2014.11.037, 2015.

Mehrotra, R. and Sharma, A.: A Multivariate Quantile-Matching Bias Correction Approach with Auto- and Cross-Dependence across Multiple Time Scales: Implications for Downscaling, J. Climate, 29, 3519-3539, https://doi.org/10.1175/JCLI-D-150356.1, 2016.

Michelangeli, P., Vrac, M., and Loukos, H.: Probabilistic downscaling approaches: application to wind cumulative distribution functions, Geophys. Res. Lett., 36, L11708, https://doi.org/10.1029/2009GL038401, 2009.

Muerth, M. J., Gauvin St-Denis, B., Ricard, S., Velázquez, J. A., Schmid, J., Minville, M., Caya, D., Chaumont, D., Ludwig, R., and Turcotte, R.: On the need for bias correction in regional climate scenarios to assess climate change impacts on river runoff, Hydrol. Earth Syst. Sci., 17, 1189-1204, https://doi.org/10.5194/hess-17-1189-2013, 2013.

Müller, C., Bondeau, A., Popp, A., Waha, K., and Fader, M.: Climate Change Impacts on Agricultural Yields, Tech. rep., World Bank, Washington, DC, available at: https://openknowledge. worldbank.org/handle/10986/9065 (last access: 1 June 2018), 2010.

Nelsen, R. B.: An Introduction to Copulas, 2nd edition, Springer, New-York, 2006.
Oettli, P., Sultan, B., Baron, C., and Vrac, M.: Are regional climate models relevant for crop yield prediction in West Africa?, Environ. Res. Lett, 6, 014008, https://doi.org/10.1088/17489326/6/1/014008, 2011.

Piani, C. and Haerter, J. O.: Two dimensional bias correction of temperature and precipitation copulas in climate models, Geophys. Res. Lett., 39, L20401, https://doi.org/10.1029/2012GL053839, 2012.

Quintana-Segui, P., Le Moigne, P., Durand, Y., Martin, E., Habets, F., Baillon, M., Canellas, C., Franchistéguy, L., and Morel, S.: Analysis of near surface atmospheric variables: validation of the SAFRAN analysis over France, J. Appl. Meteorol. Clim., 47, 92-107, 2008 (data available at: https://donneespubliques.meteofrance.fr/?fond=produit\&id_ produit $=230 \& i d \_r u b r i q u e=40$, last access: 1 June 2018).

Samuelsson, P., Jones, C. G., Will'En, U., Ullerstig, A., Gollvik, S., Hansson, U., Jansson, E., Kjellström, C., Nikulin, G., and Wyser, K.: The Rossby centre regional climate model RCA3: model description and performance, Tellus, 63A, 4-23, https://doi.org/10.1111/j.1600-0870.2010.00478.x, 2011.

Schmidli, J., Frei, C., and Vidale, P.: Downscaling From Gcm Precipitation: A Benchmark For Dynamical And Statistical Downscaling Methods, J. Climatol., 26, 679-689, https://doi.org/10.1002/joc.1287, 2006.

Schneider, C., Laizé, C. L. R., Acreman, M. C., and Flörke, M.: How will climate change modify river flow regimes in Europe?, Hydrol. Earth Syst. Sci., 17, 325-339, https://doi.org/10.5194/hess-17-325-2013, 2013.

Schölzel, C. and Friederichs, P.: Multivariate non-normally distributed random variables in climate research - introduction to the copula approach, Nonlin. Processes Geophys., 15, 761-772, https://doi.org/10.5194/npg-15-761-2008, 2008.

Skamarock, W., Klemp, J., Dudhia, J., Gill, D., Barker, M., Duda, K., Huang, X., Wang, W., and Powers, J.: A description of the Advanced Research WRF Version 3, Tech. Note NCAR/TN475+STR, NCAR, Natl. Cent. for Atmos. Res., Boulder, Colo, 2008.

Sklar, A.: Fonctions de répartition à $\mathrm{n}$ dimensions et leurs marges, Tech. Rep. 229-231, Publ. Inst. Statist. Univ. Paris 8, 1959.

Tisseuil, C., Vrac, M., Grenouillet, G., Gevrey, M., Oberdorff, T., Wade, A., and Lek, S.: Strengthening the link between hydro-climatic downscaling and species distribution modelling: Climate change impacts on freshwater biodiversity, Sci. Total Environ., 424, 193-201, https://doi.org/10.1016/j.scitotenv.2012.02.035, 2012.

Tramblay, Y., Ruelland, D., Somot, S., Bouaicha, R., and Servat, E.: High-resolution Med-CORDEX regional climate model simulations for hydrological impact studies: a first evaluation of the ALADIN-Climate model in Morocco, Hydrol. Earth Syst. Sci., 17, 3721-3739, https://doi.org/10.5194/hess-17-3721-2013, 2013.

Verkade, J., Brown, J., Weerts, A., and Reggiani, P. Weerts, A. H.: Post-processing ECMWF precipitation and temperature ensemble reforecasts for operational hydrologic forecasting at various spatial scales, J. Hydrol., 501, 73-91, https://doi.org/10.1016/j.jhydrol.2013.07.039, 2013.

Vigaud, N., Vrac, M., and Caballero, Y.: Probabilistic Downscaling of GCM scenarios over southern India, J. Climatol., 33, 12481263, https://doi.org/10.1002/joc.3509, 2013. 
Voisin, N., Schaake, J. C., and Lettenmaier, D. P.: Calibration and downscaling methods for quantitative ensemble precipitation forecasts, Weather Forecast., 25, 1603-1627, 2010.

Volosciuk, C., Maraun, D., Vrac, M., and Widmann, M.: A combined statistical bias correction and stochastic downscaling method for precipitation, Hydrol. Earth Syst. Sci., 21, 16931719, https://doi.org/10.5194/hess-21-1693-2017, 2017.

Vrac, M. and Friederichs, P.: Multivariate - Intervariable, Spatial, and Temporal - Bias Correction, J. Climate, 28, 218-237, https://doi.org/10.1175/JCLI-D-14-00059.1, 2015.

Vrac, M. and Vaittinada Ayar, P.: Influence of Bias Correcting Predictors on Statistical Downscaling Models, J. Appl. Meteorol. Clim., 56, 5-26, https://doi.org/10.1175/JAMC-D-160079.1, 2017.

Vrac, M., Billard, L., Diday, E., and Chédin, A.: Copula Analysis of Mixture Models, Computation. Stat., 27, 427, https://doi.org/10.1007/s00180-011-0266-0, 2011.

Vrac, M., Drobinski, P., Merlo, A., Herrmann, M., Lavaysse, C., Li, L., and Somot, S.: Dynamical and statistical downscaling of the French Mediterranean climate: uncertainty assessment, Nat. Hazards Earth Syst. Sci., 12, 2769-2784, https://doi.org/10.5194/nhess-12-2769-2012, 2012.
Vrac, M., Noël, T., and Vautard, R.: Bias correction of precipitation through Singularity Stochastic Removal: Because occurrencesmatter, J. Geophys. Res.-Atmos., 121, 5237-5258, https://doi.org/10.1002/2015JD024511, 2016.

Wheeler, T. and von Braun, J.: Climate Change Impacts on Global Food Security, Science, 341, 508-513, https://doi.org/10.1126/science.1239402, 2013.

Wong, G., Maraun, D., Vrac, M., Widmann, M., Eden, J., and T. Kent, T.: Stochastic model output statistics for bias correcting and downscaling precipitation including extremes, J. Climate, 27, 6940-6959, https://doi.org/10.1175/JCLI-D-1300604.1, 2014.

$\mathrm{Xu}, \mathrm{C}$.-Y.: From GCMs to river flow: a review of downscaling methods and hydrologic modelling approaches, Prog. Phys. Geog., 23, 229-249, https://doi.org/10.1177/030913339902300204, 1999.

Yiou, P., Jézéquel, A., Naveau, P., Otto, F., Vautard, R., and Vrac, M.: A statistical framework for conditional extreme event attribution, Adv. Stat. Clim. Meteorol. Oceanogr., 3, 17-31, https://doi.org/10.5194/ascmo-3-17-2017, 2017. 